
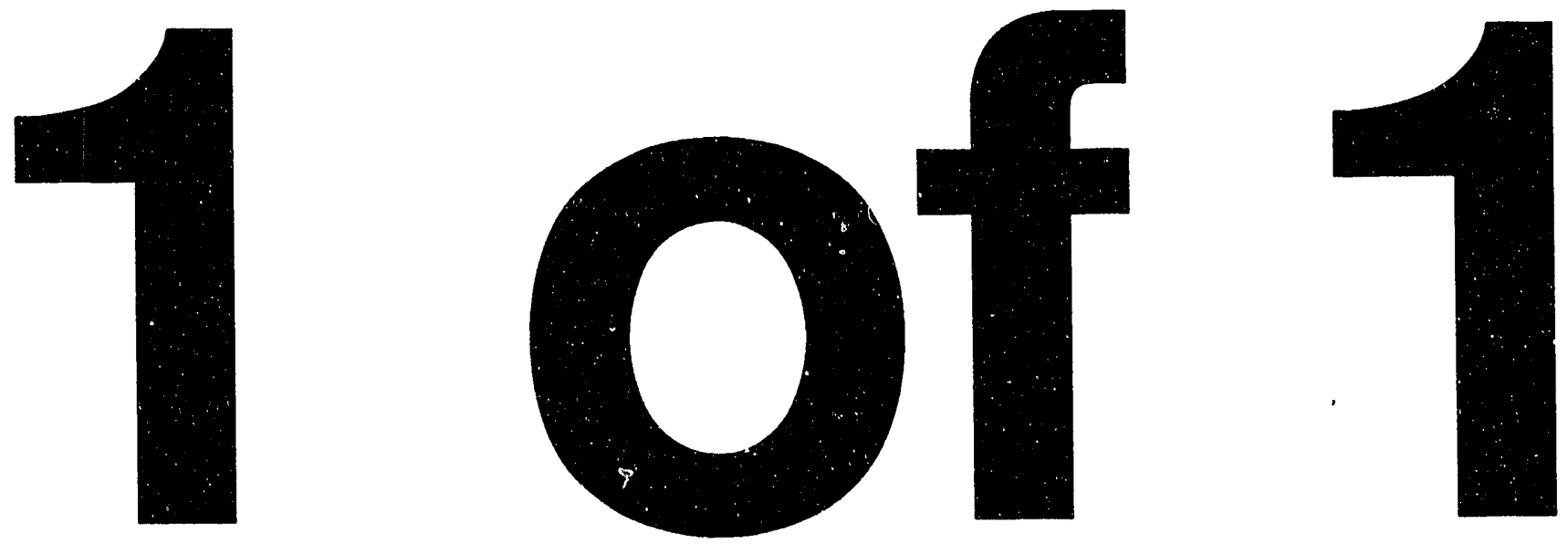
ORNL/TM-12353

Engineering Technology Division

FUEL PLATE STABILITY EXPERIMENTS AND ANALYSIS FOR THE ADVANCED NEUTRON SOURCE

\author{
W. F. Swinson \\ R. L. Battiste \\ C. R. Luttrell \\ G. T. Yahr
}

May 1993

Prepared by the

OAK RIDGE NATIONAL LABORATORY

Oak Ridge, Tennessee 37831 managed by

MARTIN MARIETTA ENERGY SYSTEMS, INC.

for the U.S. Department of Energy

under contract No. DE-AC(15-84OR21400 


\section{CONTENTS}

\begin{tabular}{|c|c|}
\hline \multirow{2}{*}{ LIST OF FIGURES } & Page \\
\hline & $\mathrm{v}$ \\
\hline ACRONYMS AND SYMBOLS & vii \\
\hline ACKNOWLEDGMENTS & ix \\
\hline ABSTRACT & 1 \\
\hline 1. INTRODUCTION & 1 \\
\hline 2. EXPERIMENTAL ARRANGEMENT ..... & 3 \\
\hline 3. PLATE EXPERIMENTAL DATA & 13 \\
\hline 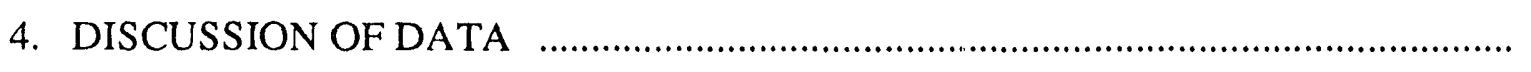 & 29 \\
\hline 5. CONCLUSIONS & 35 \\
\hline 6. REFERENCES ........... & 37 \\
\hline APPENDIX A: MODEL THEORY & 39 \\
\hline APPENDIX B: PRESSURE DROP & 40 \\
\hline
\end{tabular}




\section{LIST OF FIGURES}

Figure

Page

1 ANS conceptual core design

2 ANS fuel elements are annular arrays of $1.27-\mathrm{mm}$-thick involute plates with a $1.27-\mathrm{mm}$ gap between plates

3 Schematic of ANS fuel plate test loop

4 Flow straightener for upper element plate test

5 Upper element plate test section

6 Rig for calibrating strain gages to indicate plate deflection $\quad$................................ 9

$7 \quad$ Formed epoxy involute plate and mandrel .................................................... 10

8 Assembled lower element test model f............................................................ 11

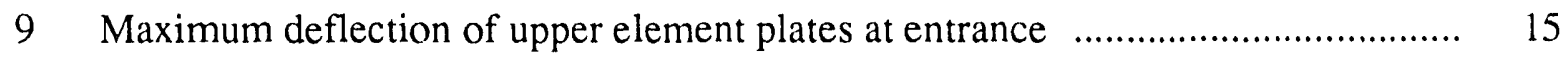

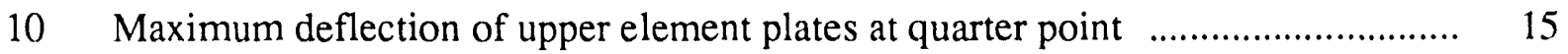

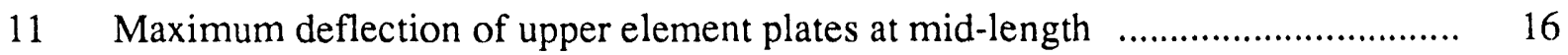

12 Maximum deflection of upper element plates at three-quarter point ................... 16

13 Maximum deflection of upper element plates at exit ..................................... 17

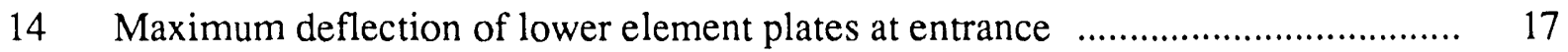

15 Maximum deflection of lower element plates at quarter point ............................ 18

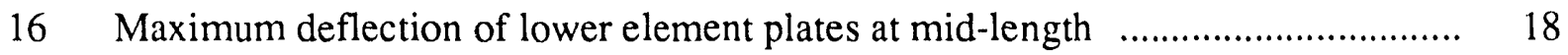

17 Maximum deflection of lower element plates at three-quarter point ................... 19

18 Maximum deflection of lower element plates at exit ....................................... 19

19 Maximum deflection of upper element plate 4 vs axial position ......................... 20

20 Maximum deflection of upper element plate $6 \mathrm{vs}$ axial position ........................ 20

21 Maximum deflection of upper element plate 5 vs axial position .......................... 21

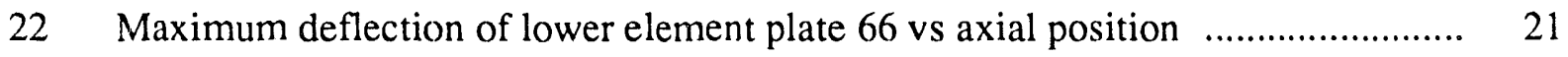

23 Maximum deflection of lower element plate $55 \mathrm{vs}$ axial position ....................... 22

24 Maximum deflection of lower element plate $44 \mathrm{vs}$ axial position ....................... 22

25 Maximum deflection and differential pressure on upper element plates at entrance

26 Maximum deflection and differential pressure on upper element plates at quarter point

27 Maximum deflection and differential pressure on upper element plates at mid-length

28 Maximum deflection and differential pressure on upper element plates at three-quarter point 
29 Maximum deflection and differential pressure on upper element plates at exit

30 Maximum deflection and differential pressure on lower element plates at entrance

31 Maximum deflection and differential pressure on lower element plates at quarter foint

32 Maximum deflection and differential pressure on lower element plates at mid-length

33 Maximum deflection and differential pressure on lower element plates at three-quarter point

34 Maximum deflection and differential pressure on lower element plates at exit

35 Entrance strain gage response vs time of upper element plate 6 at $36.1 \mathrm{~m} / \mathrm{s}$ flow velocity

36 Entrance strain gage response vs time of lower element plate 55 at $53.7 \mathrm{~m} / \mathrm{s}$ flow velocity

37 Maximum deflection of upper element plate 6 at entrance during the initial test with unsmoothed transition from flow straightener 30

38 Maximum deflection at entrance of single epoxy HFIR plate test

39 Comparison of dynamic pressure predictions with measured deflections at entrance for upper element plates

40 Comparison of dynamic pressure predictions with measured deflections at three-quarter point for upper element plates

41 Comparison of dynamic pressure predictions with measured deflections at entrance for lower element plates

42 Comparison of dynamic pressure predictions with measured deflections at three-quarter for lower element plates 


\section{ACRONYMS AND SYMBOLS}

$\begin{array}{ll}\text { ANS } & \text { Advanced Neutron Source } \\ \text { HFIR } & \text { High Flux Isotope Reactor } \\ \text { ETR } & \text { Engineering Test Reactor } \\ \text { MTR } & \text { Materials Test Reactor } \\ A & \text { Channel cross-sectional area } \\ D_{\mathrm{H}} & \text { Hydraulic diameter } \\ \delta & \text { Plate maximum deflection } \\ \mathrm{E} & \text { Plate modulus of elasticity } \\ f & \text { Friction factor } \\ g & \text { Gravitational constant } \\ g_{\mathrm{c}} & \text { Dimensional constant } \\ \mathrm{L} & \text { Dimension parameter } \\ \mu & \text { Plate Poisson's ratio } \\ \mu_{\mathrm{f}} & \text { Coolant viscosity } \\ \Delta p & \text { Pressure difference across a plate } \\ \Delta P_{\mathrm{L}} & \text { Pressure drop along plate length } \\ P_{\mathrm{W}} & \text { Wetted perimeter of flow channel } \\ \pi_{i} & \text { Dimensionless term (subscripts are identified in text as used) } \\ R_{\mathrm{e}} & \text { Reynolds number } \\ \rho_{\mathrm{f}} & \text { Coolant density } \\ V & \text { Coolant velocity }\end{array}$




\section{ACKNOWLEDGMENTS}

The authors wish to thank W. K. Sartory for discussions of his related analytical work. Special thanks are due to D. T. Godwin for his help in conducting the experiment. 


\title{
FUEL PLATE STABILITY EXPERIMENTS AND ANAL'YSIS FOR THE ADVANCED NEUTRON SOURCE
}

\author{
W. F. Swinson \\ R. L. Battiste \\ C. R. Luttrell \\ G. T. Yahr
}

The planned reactor for the Advanced Neutron Source (ANS) will use closely spaced arrays of involute-shaped fuel plates that will be cooled by water flowing through the channels between the plates. There is concern that at certain coolant flow velocities, adjacent plates may deflect and touch, with resulting failure of the plates. Experiments have been conducted at the Oak Ridge National Laboratory to examine this potential phenomenon. Results of the experiments and comparison with analytical predictions are reported. The tests were conducted using fullscale epoxy plate models of the aluminum/uranium silicide ANS involute-shaped fuel plates. Use of epoxy plates and model theory allowed lower flow velocities and pressures to explore the potential failure mechanism. Plate deflections and channel pressures as functions of the flow velocity are examined. Comparisons with mathematical models are noted.

\section{INTRODUCTION}

The planned Advanced Neutron Source ${ }^{1,2}$ (ANS) and several existing reactors-including the High Flux Isotope Reactor (HFIR), the Engineering Test Reactor (ETR), and the Materials Test Reactor (MTR)-use closely spaced arrays of fuel plates that are cooled by water flowing through the channels between the plates. In tests at Oak Ridge ${ }^{3}$ and in early ETR tests, 4,5 failures have occurred when adjacent plates touched. The structural response, including the potential collapse, of the ANS fuel plates to coolant flow is being examined by experiment and analyses. Some of this work is reported in this paper.

Miller ${ }^{6}$ developed a model for a collapse flow phenomenon, assuming constant mass flow in each channel, which predicted plate collapse at a specific flow velocity. This collapse velocity has come to be identified as the critical velocity. Groninger and Kane, ${ }^{7}$ Smissaert, ${ }^{8}$ and Zabriskie $^{9}$ did some experimental work on flat plates to investigate the critical velocity model. In most instances maximum deflection of the plates occurred at the entrance to the flow channel and increased as the flow velocity increased. At flow velocities of approximately twice Miller's calculated critical velocity, deflections became large, plates began to touch, and flutter type oscillations began to occur.

Because in general the Miller model did not correlate well with flat plate experiments, because there are no data on involute plates, and because it is desirable for a designer to know the plate deflection as a function of flow velocity, experiments with the proposed ANS involute plates are being conducted. 


\section{EXPERIMENTAL ARRANGEMENT}

The proposed ANS core is composed of two annular assemblies of involute plates as shown in Fig. 1. The upper element has an inside radius of $175 \mathrm{~mm}$, and the lower element has an inside radius of $102 \mathrm{~mm}$. The individual plates are involute in shape and use aluminum claddings with a uranium silicide/aluminum mixture core. Figure 2 shows the general plate arrangement in the element. The plates are $1.27 \mathrm{~mm}$ thick, and the flow channels are $1.27 \mathrm{~mm}$ thick. This paper reports on the test and analysis of the upper (outer) plates and the lower (inner) plates.

The plates were modeled full scale but with epoxy material. This modeling reduced the required flow velocity [by almost a factor of 5 (see Appendix A)] and resulted in a reduction [by approximately a factor of 16 (see Appendix B)] in pressure drop to get the required flow.

Through use of the model, flow tests could be carried out to failure of the epoxy plates, and at the same time enough capacity would be available in a future test phase to test dummy aluminum plates to $15 \%$ above the operating velocity of the proposed ANS reactor. Five active plates and six flow channels were used in the test. The closed low test loop is illustrated in Fig. 3. Flow entered at the bottom of the test model and was straightened in a single involute channel (Fig. 4). The flow straightner's involute cross-sectional dimensions for the upper plates were $13.97 \mathrm{~mm}$ in width by $70.3-\mathrm{mm}$ are length. The dimensions of the flow straightener for the lower plates were $13.97 \mathrm{~mm}$ in width by $87.35-\mathrm{mm}$ are length. The longitudinal length of both flow straighteners was $527 \mathrm{~mm}$. The flow on leaving the straightener passed through the section of the test model containing the plates (Fig. 5) and then was directed into an exit chamber. Because of the boundary conditions involved, the three central plates best modeled the plate response expected in the ANS reactor as a function of coolant flow. Five strain gages were located on each of the three central plates. The gages were located with respect to the plate length at the entrance, the quarter point, the half point, the three-quarter point, and the exit. Prior to assembly of the test section, the gages were calibrated to signal the maximum plate deflection of the five cross sections noted due to a pressure difference across the plate. Figure 6 shows a plate being set up for calibration. The longitudinal boundaries were clamped to the aluminum involute mandrel. The maximum plate deflection was monitored with a dial indicator. The strain signals were recorded versus a pressure load applied to the plate. The pressure was vacuum applied by first sealing the plate ends with a pliable clay and pumping through the pressure tuber shown in Fig. 6. The four flow channels bounding the three central plates each contained live static pressure taps located in the same cross-sectional plane as the strain gages. The static pressure taps, located in the outer fixed boundary, were $1.27-\mathrm{mm}$ outside diameter and $1.07-\mathrm{mm}$ inside diameter.

The modulus of elasticity was found by optically measuring the deflection of a cantilever heam as load was applied. The average value for the material used in the upper plate model was 
2937 MPa, and for the material used in the lower plate model, $2721 \mathrm{MPa}$. These were typical of published values for epoxy. Poisson's ratio was taken as 0.35 from published values. The plates were formed by pouring a metered amount of room temperature curing epoxy onto a level, flat surface with rectangular boundaries. Before polymerization was complete, the epoxy was rolled to the desired thickness and then formed on an involute mandrel to obtain the final shape.

Figure 7 shows an epoxy plate that was formed on the mandrel; the aluminum plate shown for comparison is a HFIR plate. The plate thickness variation was found to be $\pm 0.05 \mathrm{~mm}$. The edges of the plate were trimmed with a router guided hy templates. Two rectangular epoxy strips, $1.22 \mathrm{~mm}$ in thickness $\times 12.7 \mathrm{~mm}$ in width $\times 527 \mathrm{~mm}$ in length, were epoxied to each plate. The $1.22-\mathrm{mm}$ dimension with the epoxy glue thickness held the plates apart at the desired $1.27-\mathrm{mm}$ spacing. The width dimension, $12.7 \mathrm{~mm}$, matches the thickness of the inner and outer aluminum rings shown in Fig. 5 and forms the inner and outer fixed boundaries for the flow channels. The strain gage leads and pressure tubes were taken away from the plates and channels through the spacers that formed the fixed outer boundaries. Seven plates with spacers (five active plates and two fixed boundary plates) were epoxied together as a unit and inserted into the test section. The channel spacing was found to be $1.27 \pm 0.08 \mathrm{~mm}$. The back liller shown in Figs. 4 and 5 , which also fixed the houndary plates, is room temperature curing, aluminum-filled epoxy. The three parts of the test section vere assembled by bolting them together with Teflon gaskets between each part. The completed test model of the lower element being made ready to install in the test loop is shown in Fig. 8.

The data collected, which were computer-controlled, included the flow volume from a vortex shedding meter, the 15 strain gages, the up and down stream pressures and pressure from each of the 20 pressure taps in the flow channels, and the water temperature. The entrance strain gage for the central plate was monitored with a strip chart recorder to detect plate response as a function of time and now. Generally data were recorded with the computer taking three sets of zero data (that is, without flow), which took ahout 30) s; next, the llow was adjusted to the desired value, and three sets of loaded data were recorded; and lastly, flow was stopped, and three more zero data sets were recorded. This procedure allowed for inspection of the data to detect any signilicant variation that might negate a test.

The llow in the closed test loop was supplied with a centrifugal pump capable of delivering $22 \mathrm{~L} / \mathrm{s}$ at 2.413 MPa. The flow on leaving the pump lowed along two paths (Fig. 3), one to the test model and then returning to a storage tank, and another through a bypass line to the storage tank. Each of the lines had a gear-regulated, full-flow ball valve for llow control. 


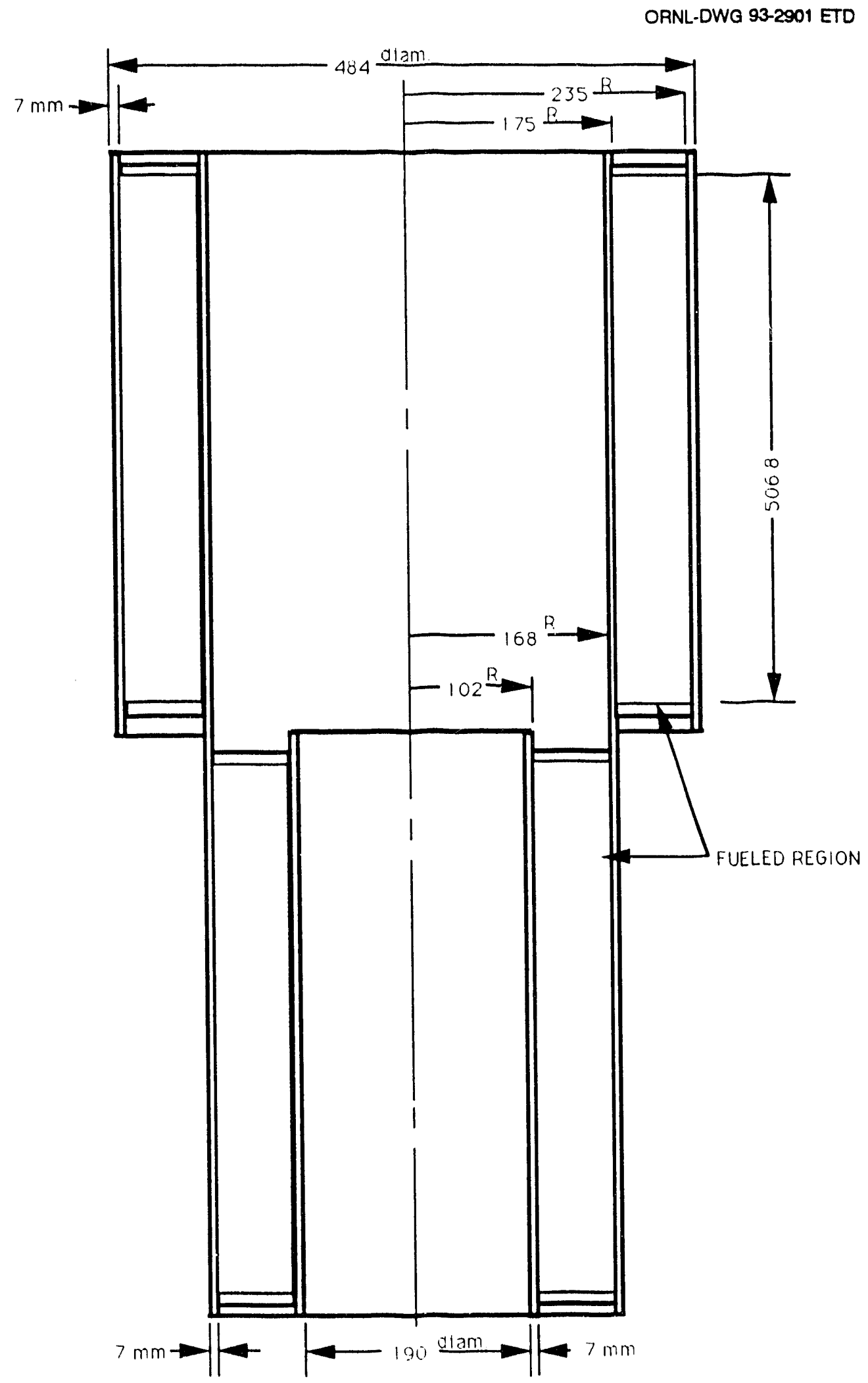

Fig. 1. ANS conceptual core design. 


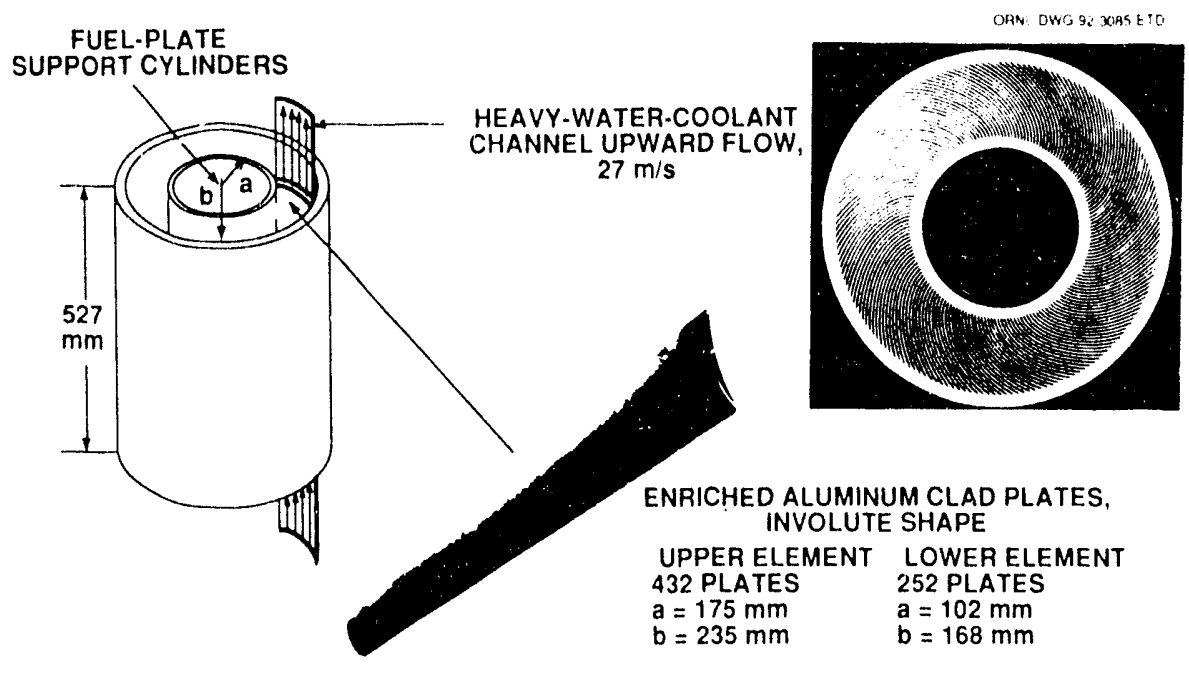

Fig. 2. ANS fuel elements are annular arrays of $1.27-\mathrm{mm}$-thick involute plates with a 1.27-mm gap between plates.

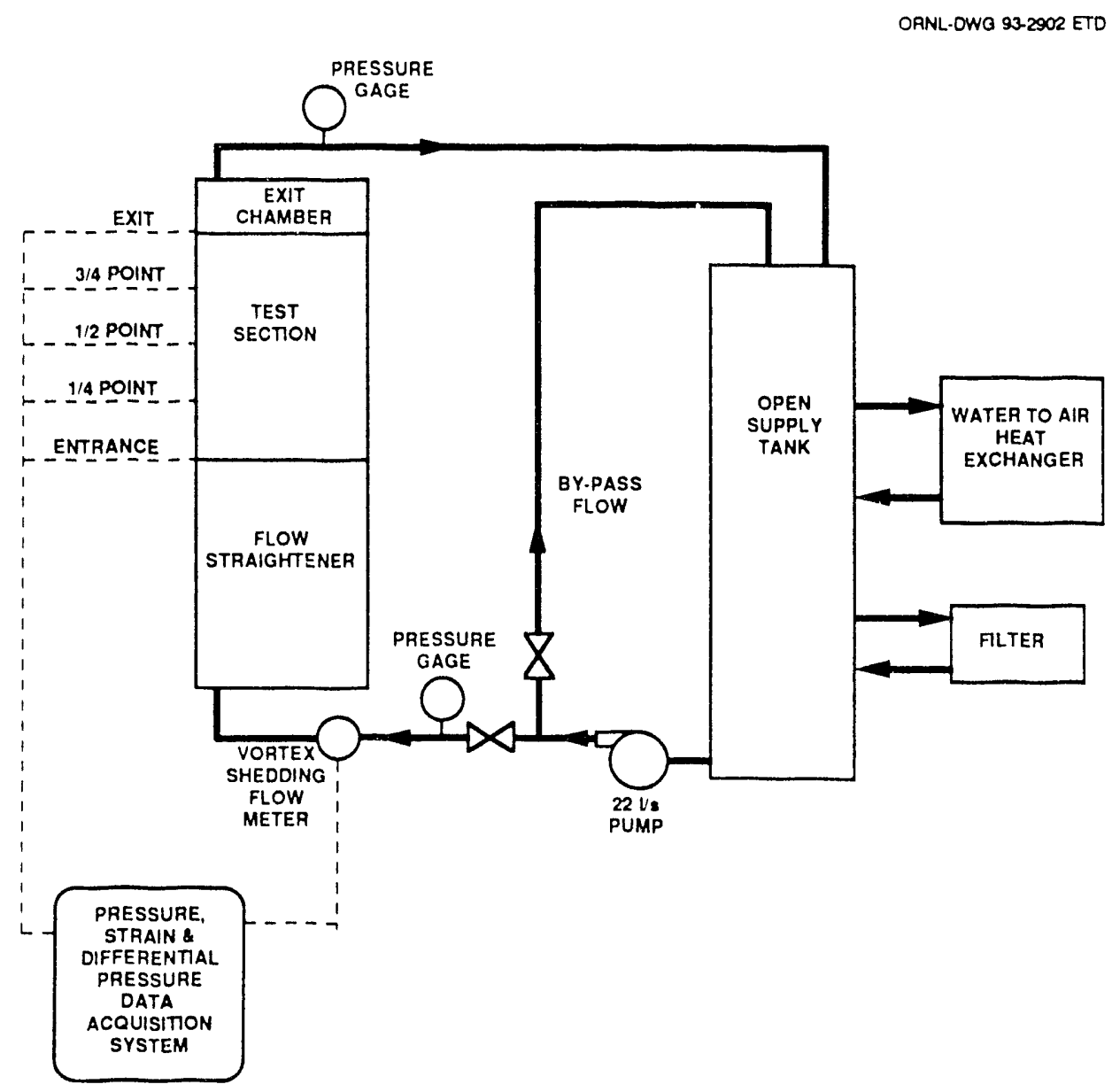

Fig. 3. Schematic of ANS fuel plate test loop. 



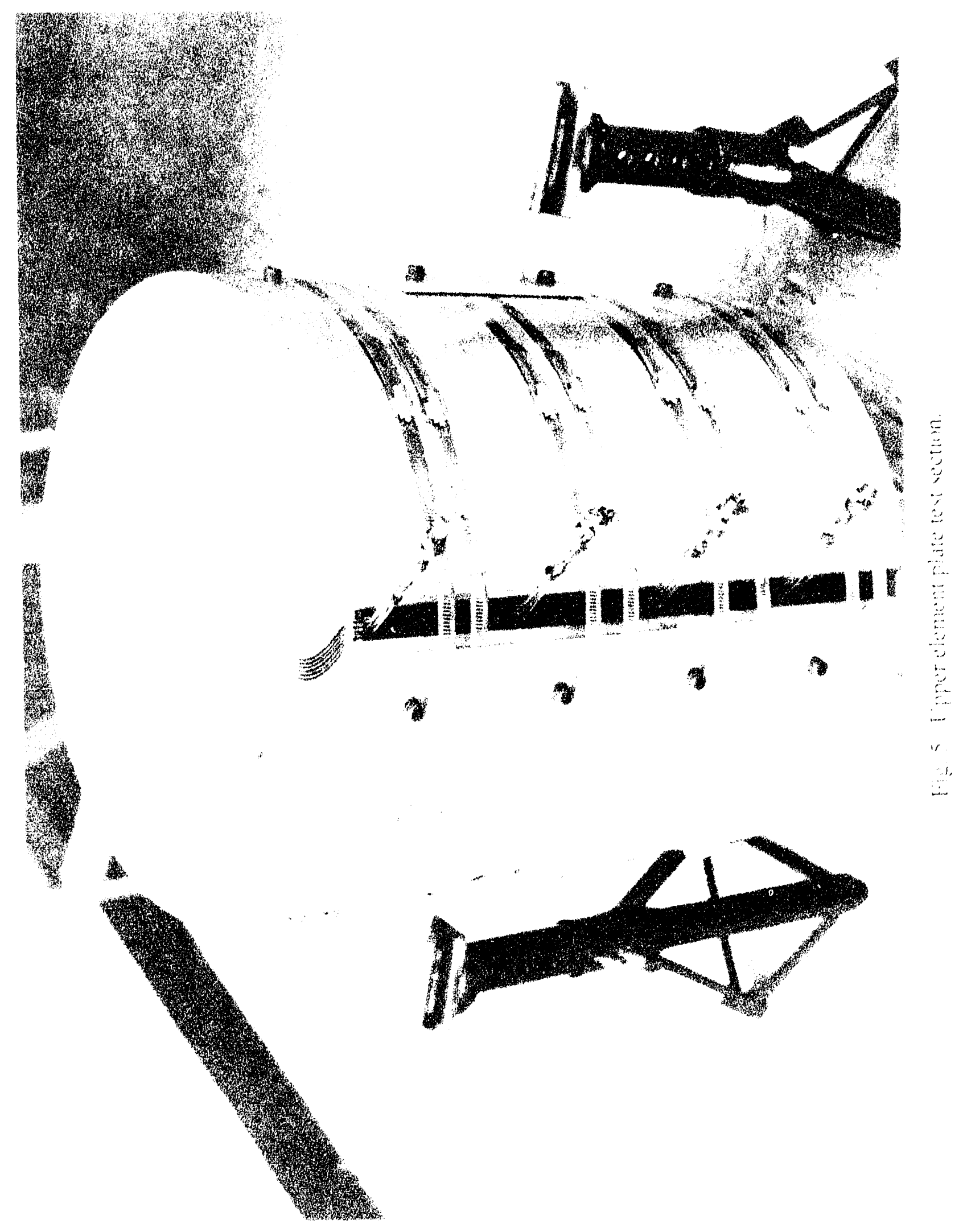




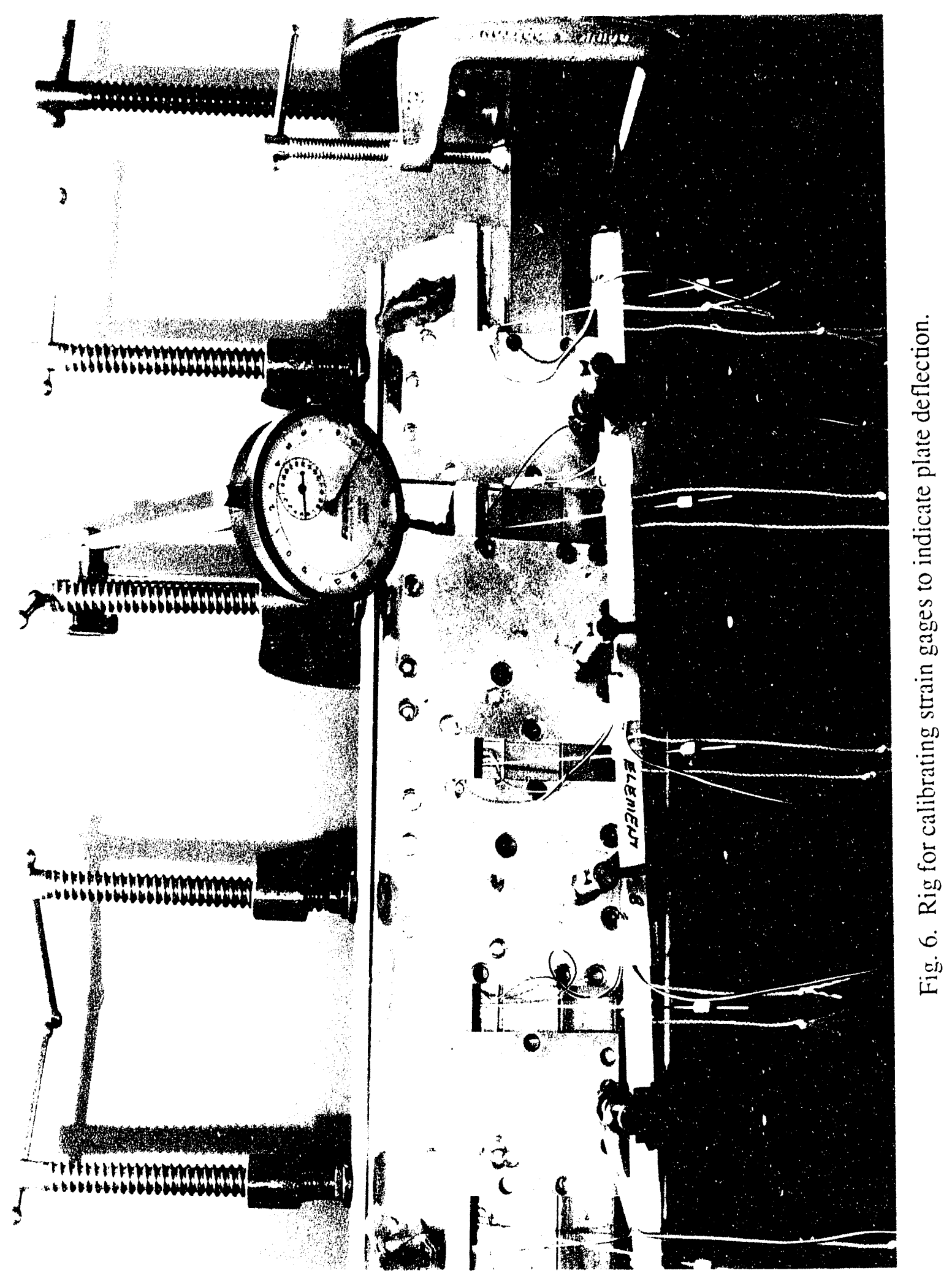



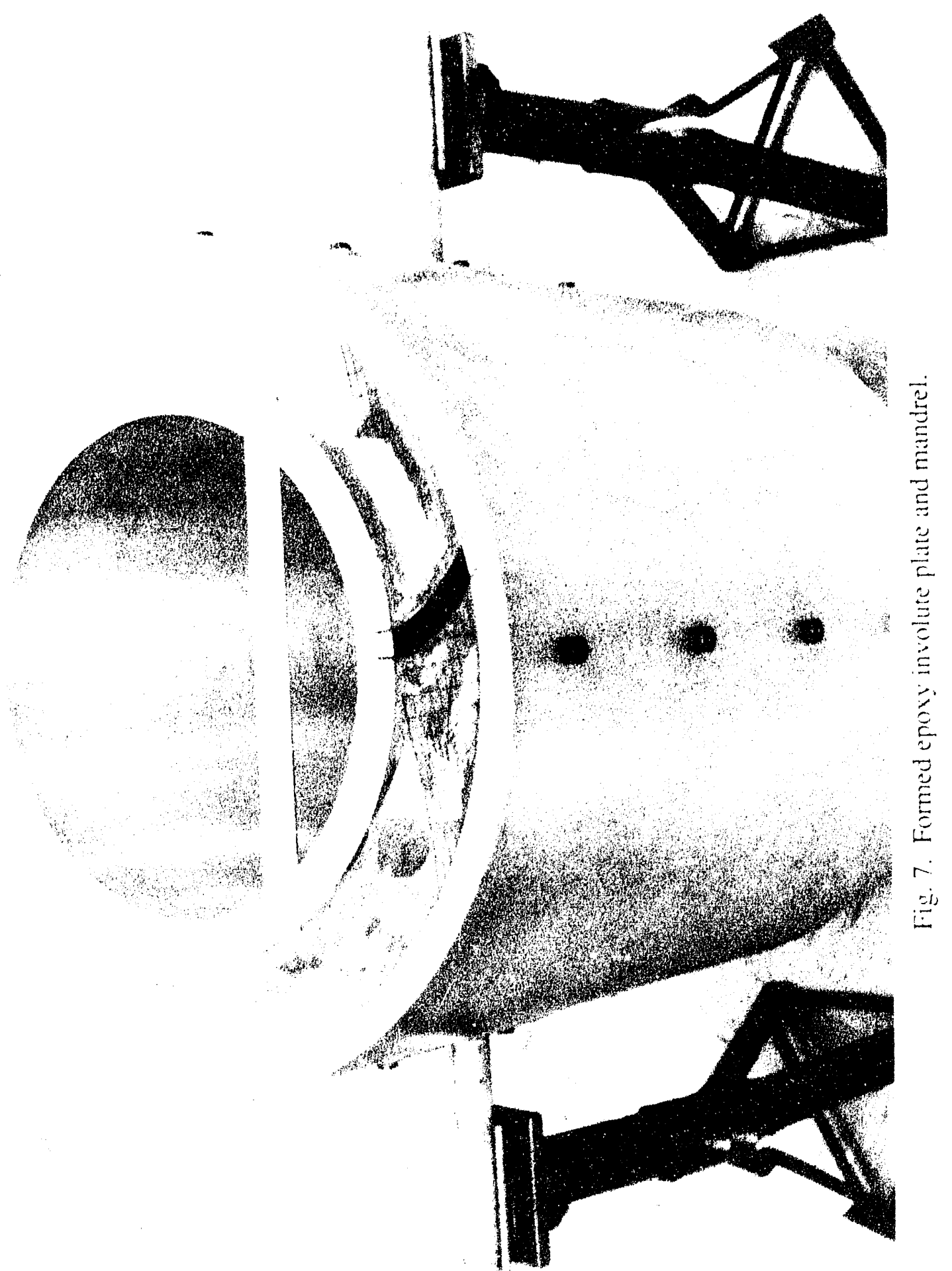


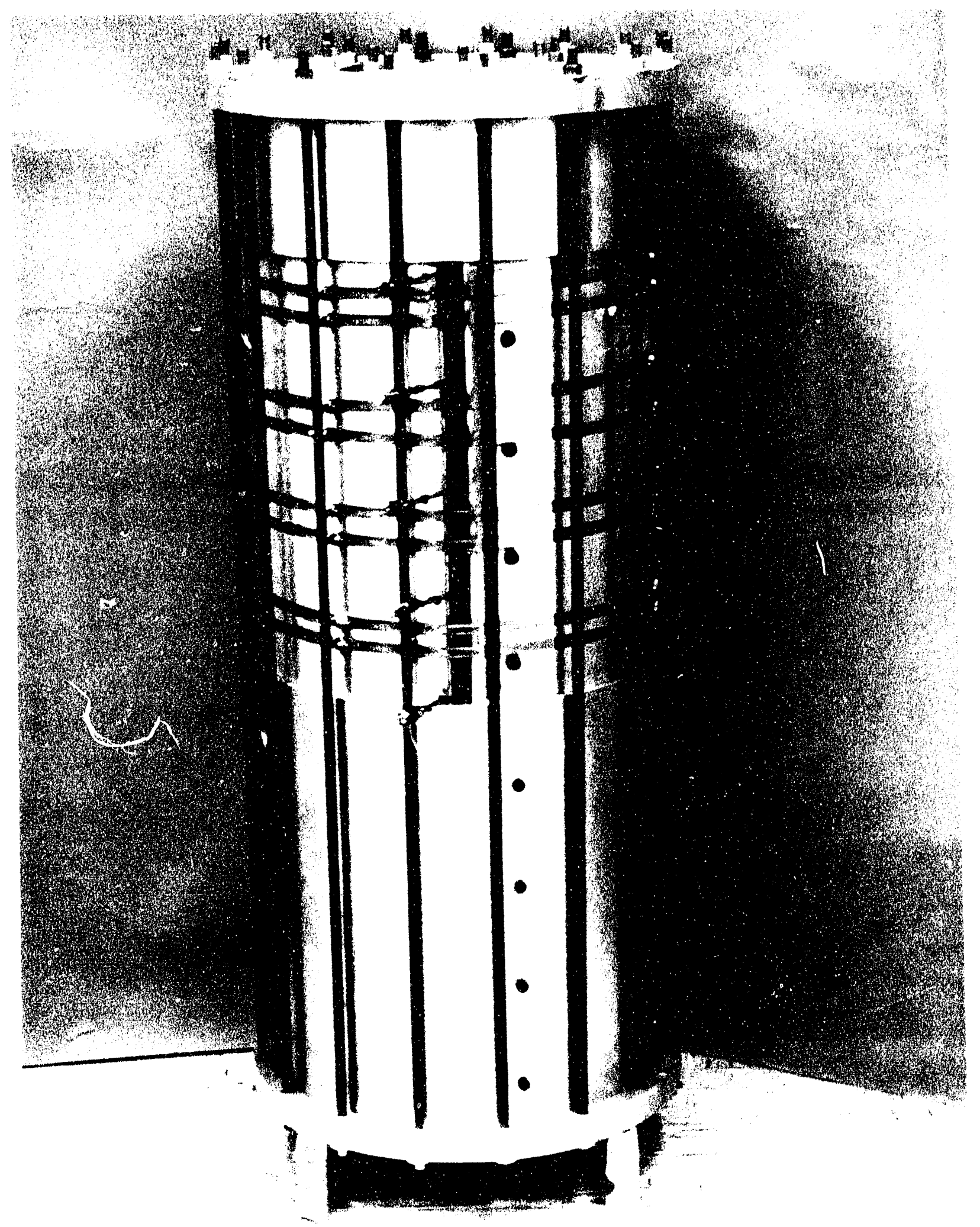

Fig. 8. Assembled lower element test model. 


\section{PLATE EXPERIMENTAL DATA}

The maximum deflections of the three instrumented upper plates and the three instrumented lower plates as a function of prototype flow velocity are shown in Figs. 9-18. To identify the instrumented plates in the test sections, the central plate for the upper element is plate 6 , to the concave side of the central plate is plate 4 , and to the convex side is plate 5 ; the central plate for the lower element is plate 55 , to the concave side of this central plate is plate 66 , and to the convex side is plate 44. This identification is noted on Figs. 9-18. For comparative purposes the positions of the three instrumented plates for the upper and lower models at the entrance, quarter, half, three-quarter, and exit cross sections are shown in the graphs. The plates are spaced $1.27 \mathrm{~mm}$ apart at zero flow velocity, but the plate coordinates change with flow velocity. The largest deflection for the three strain-gaged upper plates occurred at the entrance of plate 6 (central plate), but significant deflection was noted at the three-quarter cross section. For the lower plates at maximum flow, plate 55 (the central plate) had its maximum deflection at the three-quarter cross section, while plate 44 had its maximum deflection at the entrance.

Figures 19-24 show the maximum deflection for the upper and lower plates at cross sections designated as entrance, quarter point, half point, three-quarter point, and exit point for different prototype flow velocities. For an individual plate the maximum deflection could occur at the three-quarter point (as in upper element plate 5 and lower element plate 55), at the midpoint (as in lower element plate 66), or at the entrance (as in upper element plates 4 and 6 and lower element plate 44). A longitudinal wave-type deflection is noted in all plates and takes different forms.

Figures 25-34 again illustrate plate deflection versus prototype flow velocity, but this time the scaled pressure differences across the plates have been superimposed to illustrate how pressure difference and deflection are related. The pressure differences have been scaled by the constant that related maximum plate deflection to pressure during plate calibration. This correlation assumes that the static pressure as measured is uniform in this region of the plate. At a prototype flow velocity of approximately $33.9 \mathrm{~m} / \mathrm{s}$ (Fig. 9) the upper epoxy plates started a vibration with small amplitude. The response of the entrance strain gage as a function of time and at a prototype flow velocity of $36.1 \mathrm{~m} / \mathrm{s}$ is shown in Fig. 35. The steady-state deflection is caused by an aveiago difference in pressure across the plate and can thus be evaluated through the strain gage reading found during plate calibration. The strain variation due to vibration may be caused by local pressure variation, so it cannot be directly related to plate displacement because the change in the plate configuration is uncertain. The strain variation is smaller than the steady-state strain signal; thus, the effect on the plate deflection is considered secondary. The somewhat random frequency is about $17 \mathrm{~Hz}$. Since the vibration is an inertial response, in that it depends on the density of the 
material and the acceleration of the plate in displacing, the same vibrational response would not be expected in the aluminum prototype plates. As the flow velocity was increased, the strain amplitude of vibration dampened out almost entirely. At a flow velocity of $48.5 \mathrm{~m} / \mathrm{s}$, the plate vibration returned. The strain variation was similar to that noted at $36.1 \mathrm{~m} / \mathrm{s}$ flow velocity (Fig. 35). In this case, the strain variation was a smaller proportion of the steady-state strain but probably contributed to the fracture of one of the plates (plate 4) at the upper flow velocity limit of $56.2 \mathrm{~m} / \mathrm{s}$. The fracture was a longitudinal crack about $25 \mathrm{~mm}$ in length near the outer boundary which began at the entrance edge.

At a prototype flow velocity of approximately $29.19 \mathrm{~m} / \mathrm{s}$ (Fig. 14) a small vibration began to be evident in the central plate of the lower element. In this test, the vibration increased in amplitude with increased flow velocity and did not diminish as in the upper element test. The frequency was on the order of $12 \mathrm{~Hz}$. At a prototype flow velocity of $53.73 \mathrm{~m} / \mathrm{s}$ the entrance gage of the central plate responded as shown in Fig. 36. The lower element test model began to leak at the outer boundary near the three-quarter section, and testing was suspended. 
ORNL-DWG 93-2903 ETD

- PLT.4 DEFL * PLT.6 DEFL $\quad$ PLT.5 DEFL

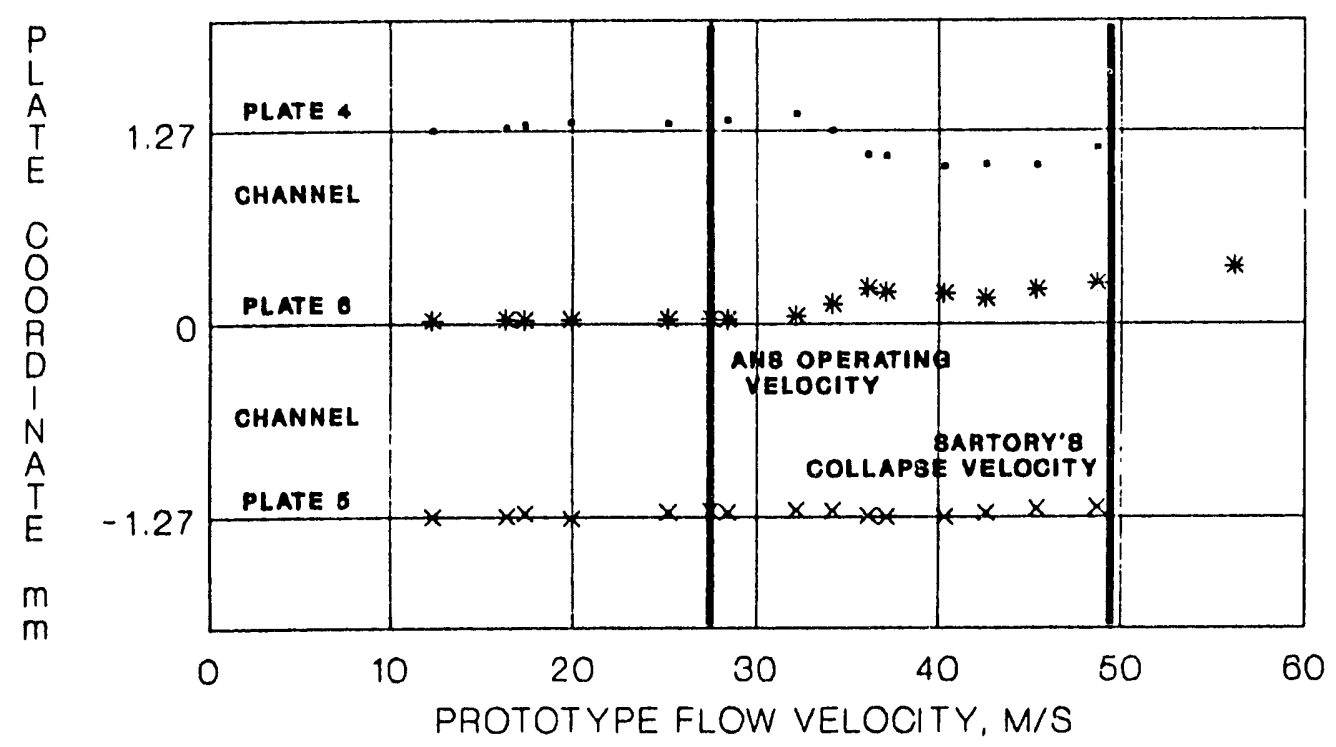

NOV 1891

Fig. 9. Maximum deflection of upper element plates at entrance.

ORNL.DWO 93-2904 ETD
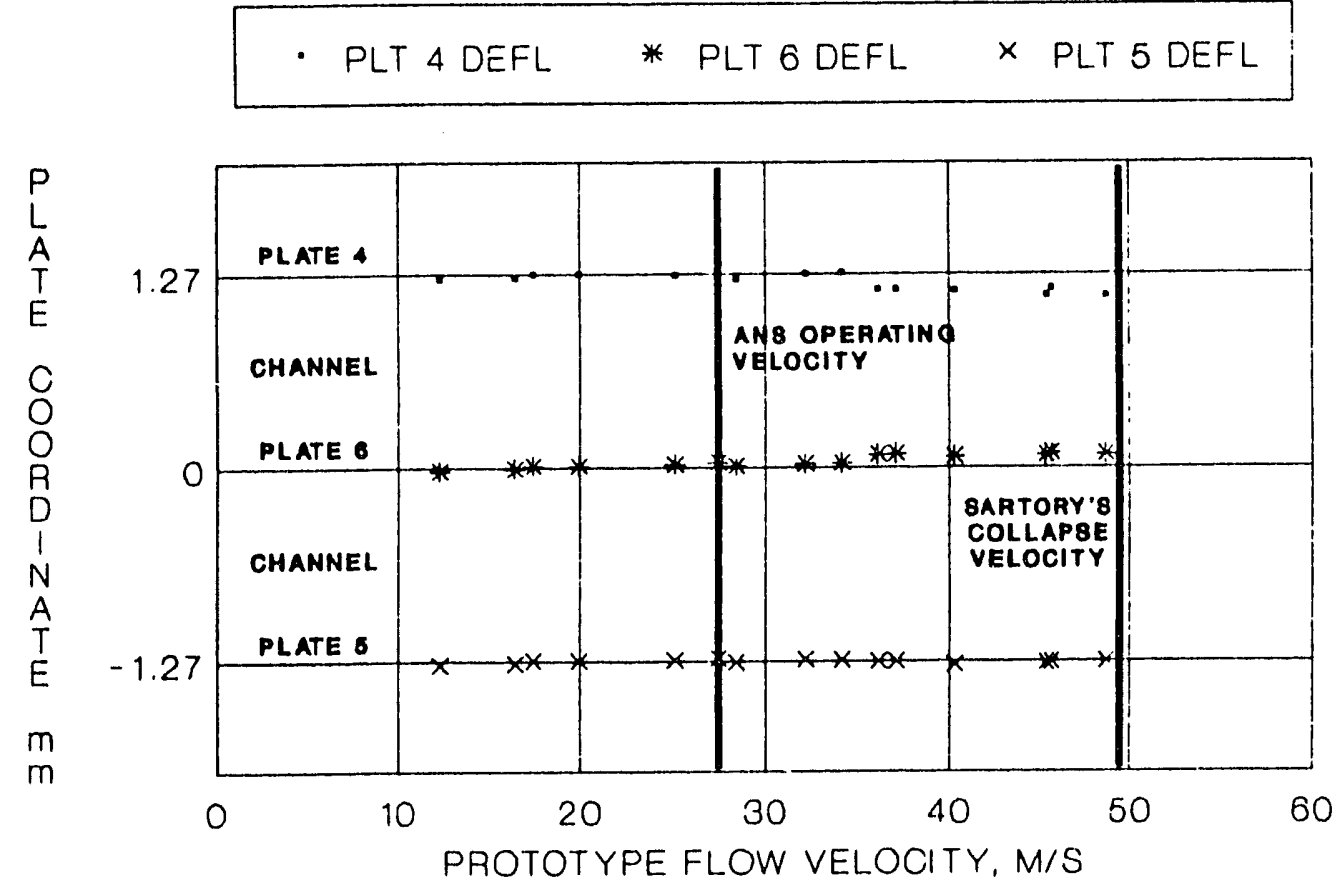

NOV 1891

Fig. 10. Maximum deflection of upper element plates at quarter point. 
ORNL.DWO 93.2905 ETD

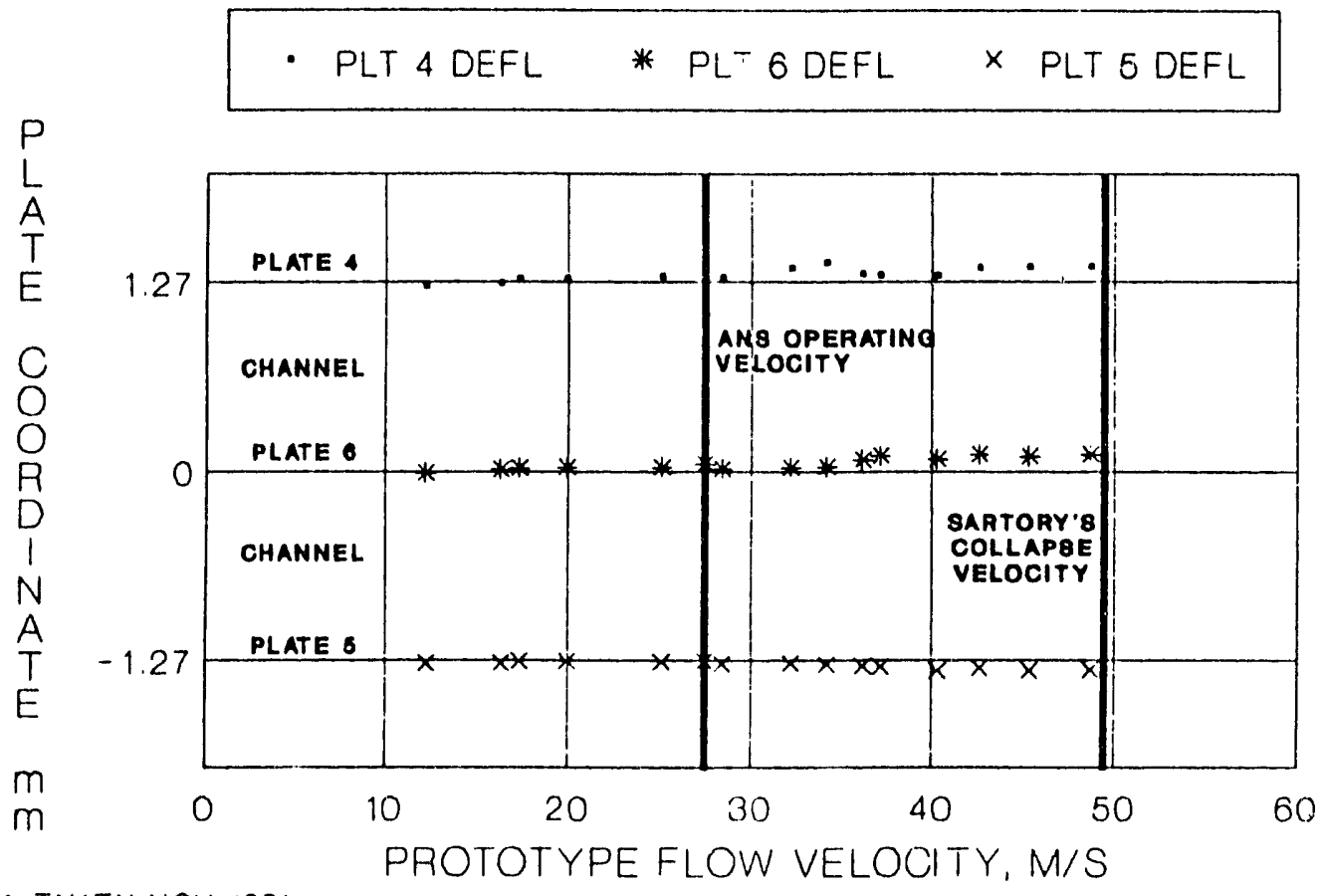

DATA TAKEN NOV 1991

Fig. 11. Maximum deflection of upper element plates at mid-length.

ORNL-DWG 93-2906 ETD

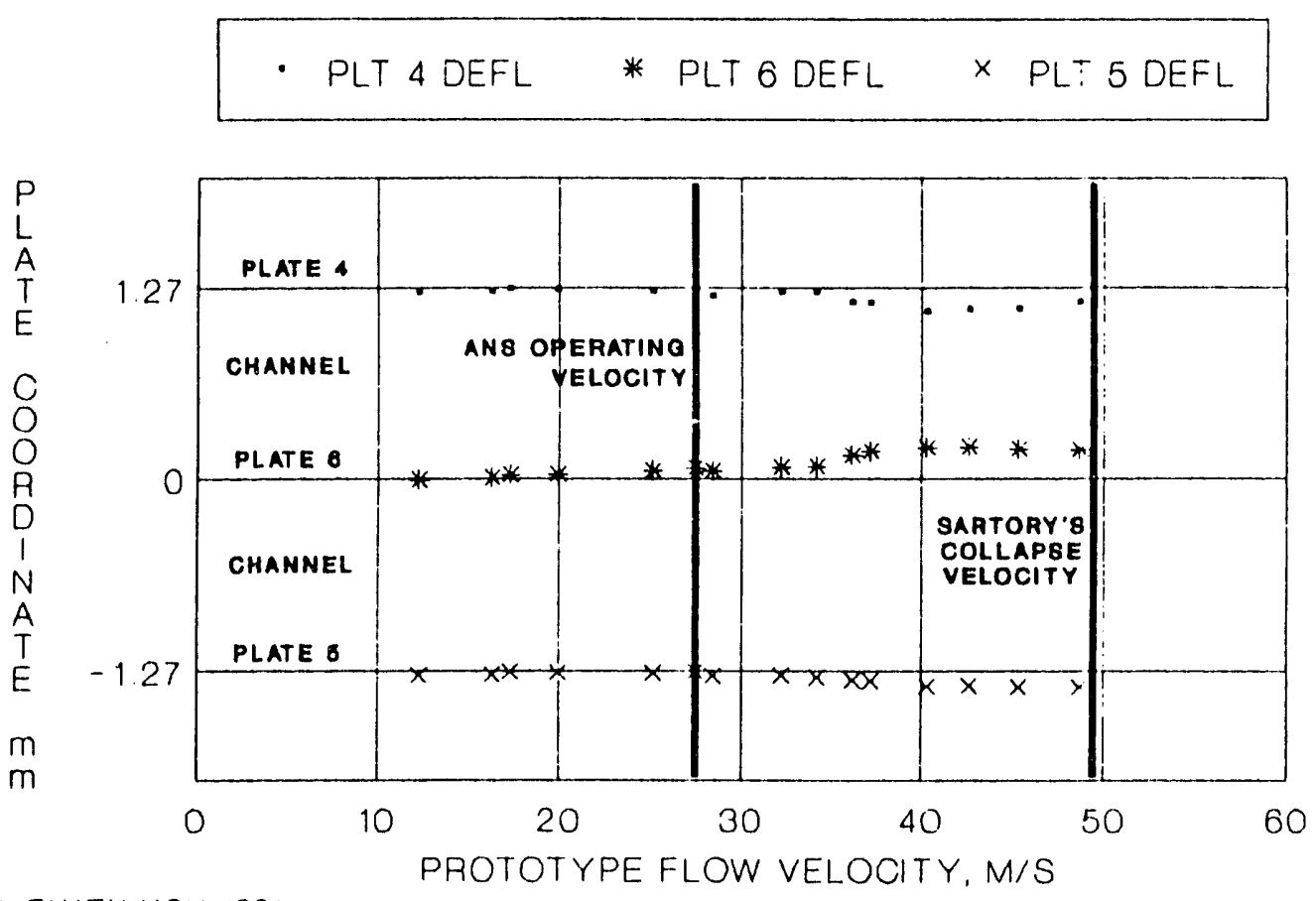

DATA TAKEN NOV 1991

Fig. 12. Maximum deflection of upper element plates at three-quarter point. 
ORNL.DWG 93-2907 ETD

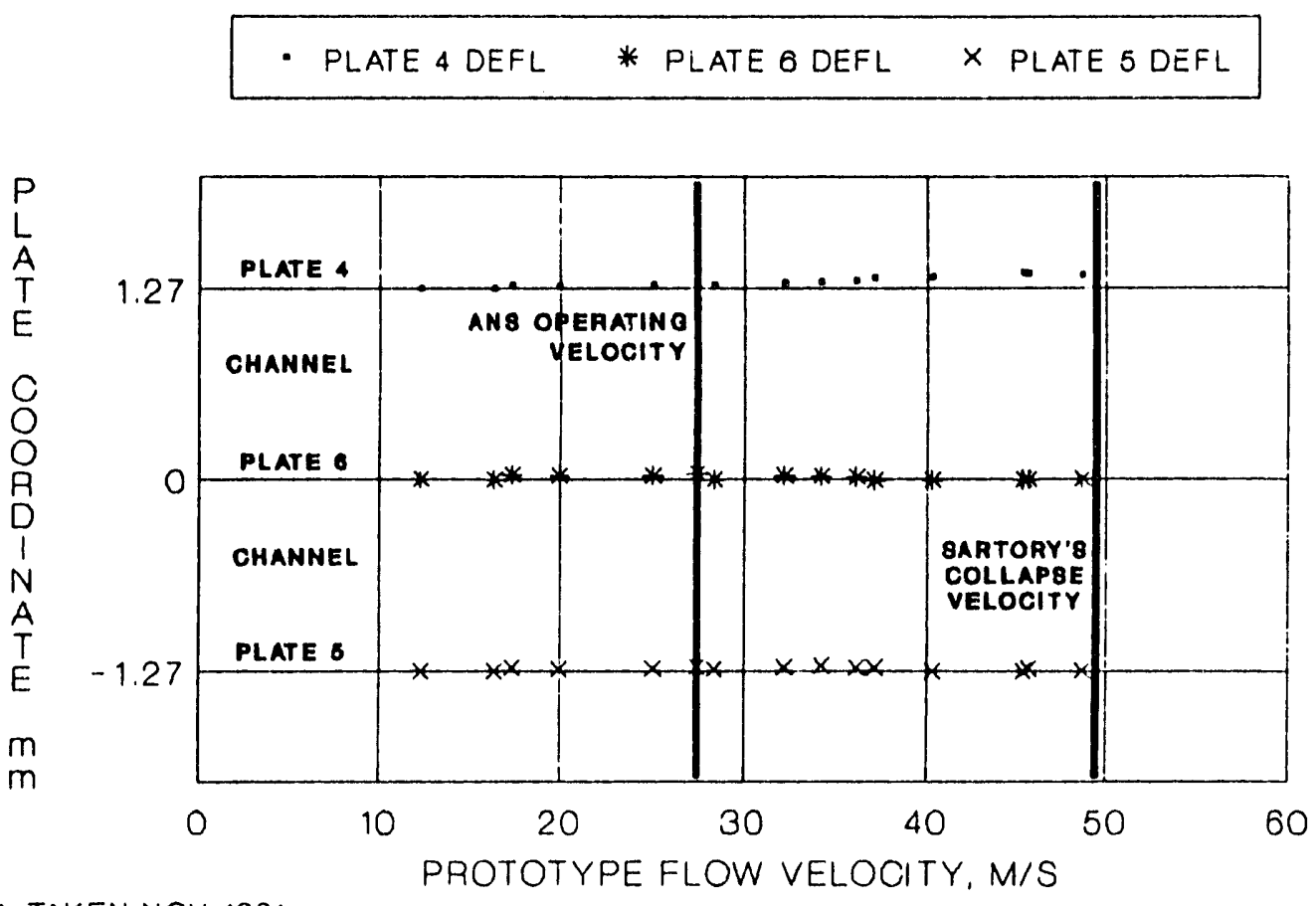

DATA TAKEN NOV 1991

Fig. 13. Maximum deflection of upper element plates at exit.

ORNL.DWG 93.2900 ETO
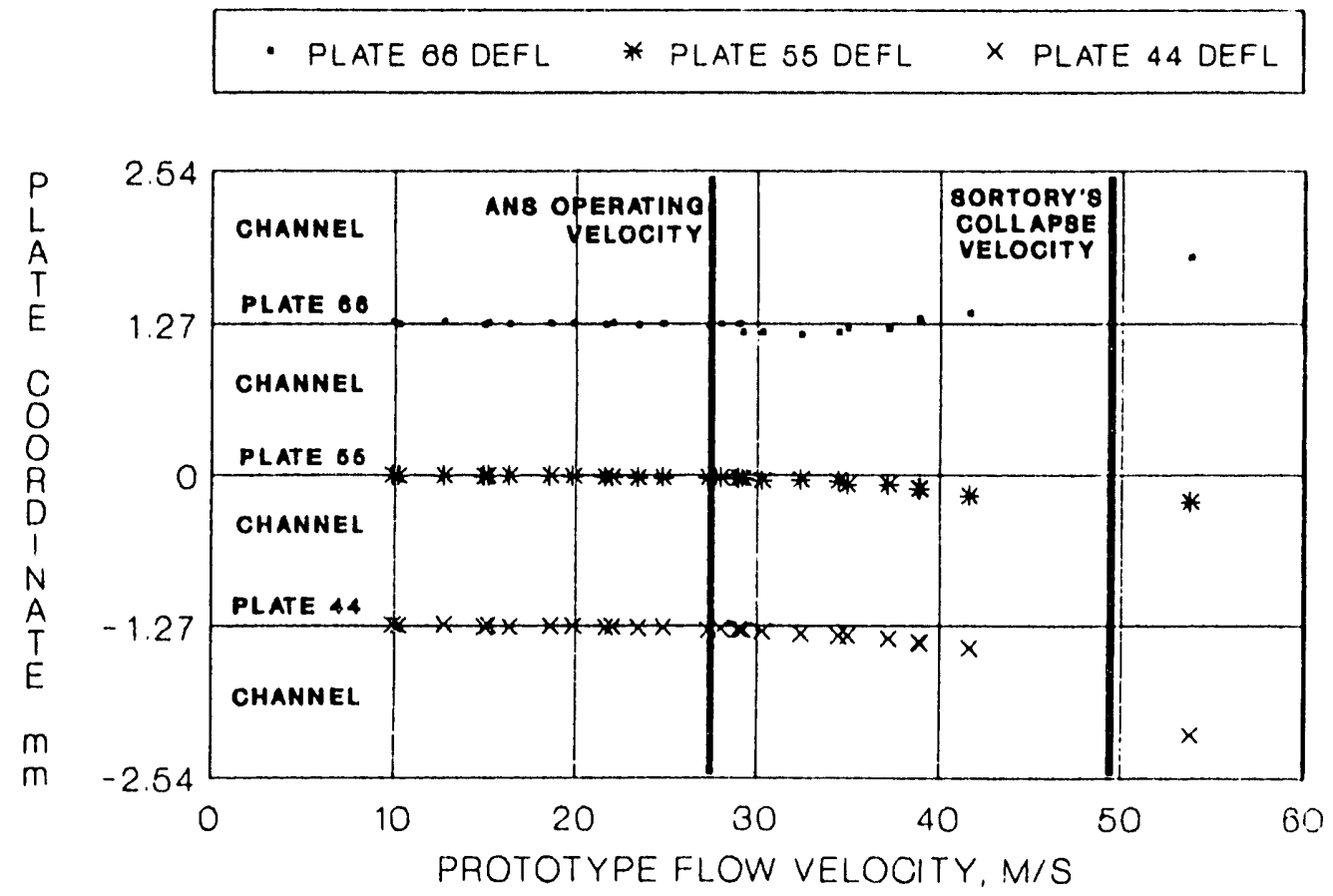

DATA TAKEN APRIL 1992

Fig. 14. Maximum deflection of lower element plates at entrance. 
OANL-DWO 93-2909 ETD
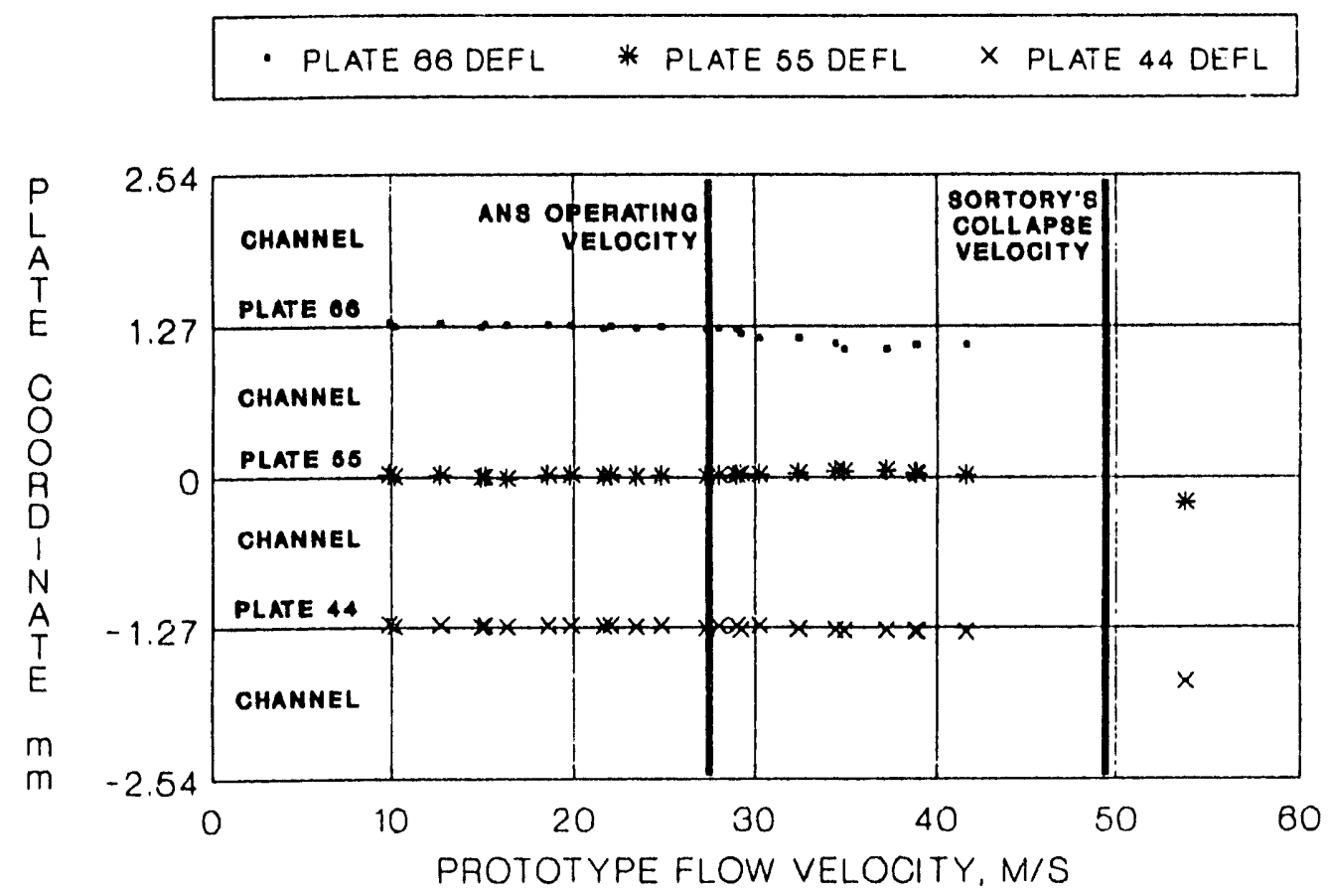

DATA TAKEN APAIL 1992

Fig. 15. Maximum deflection of lower element plates at quarter point.

ORNL.DWO 93.2910 ETD - plate 66 defl * plate 55 defl $\times$ plate 44 defl

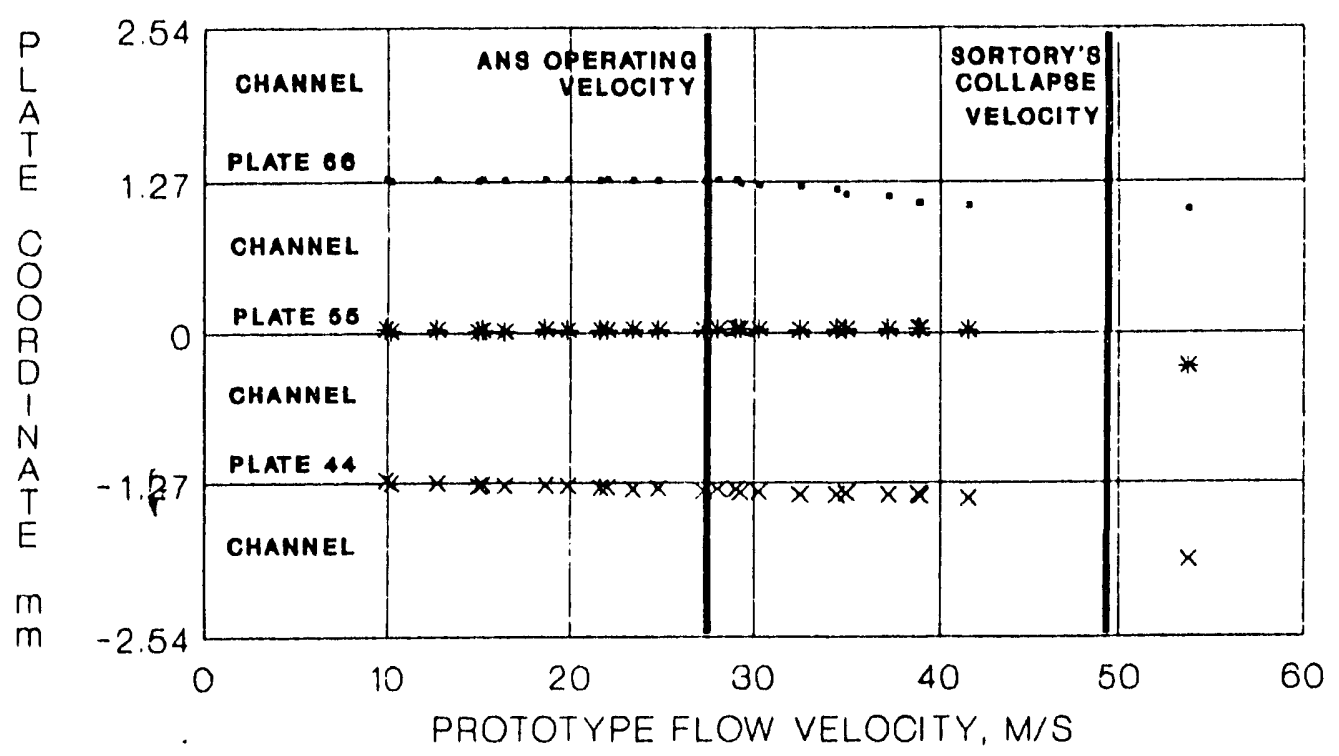

DATA TAKEN APRIL 1992

Fig. 16. Maximum deflection of lower element plates at mid-length. 
OANL.DWO 83-2911 ETD - plate 66 deFl * plate 55 defl $\times$ Plate 44 Defl

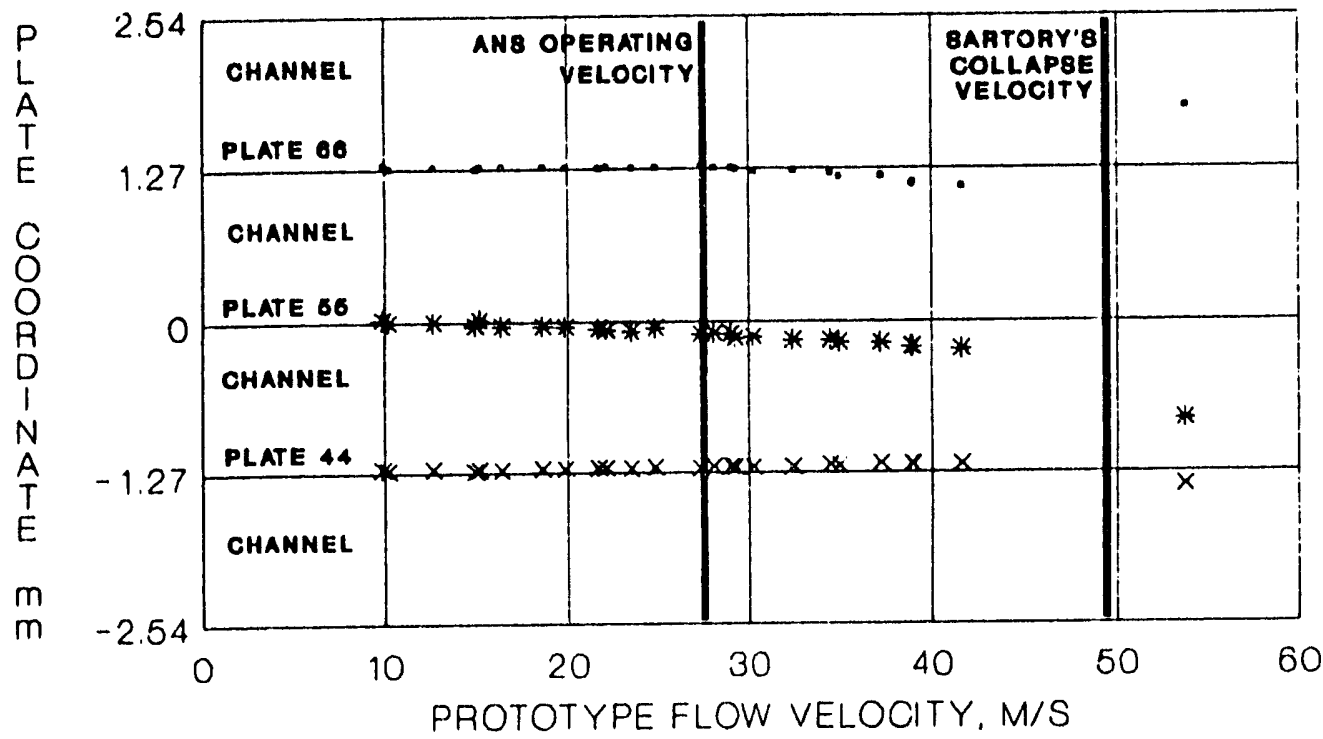

DATA TAKEN APRIL 1992

Fig. 17. Maximum deflection of lower element plates at three-quarter point.

ORNL.DWG 93.2912 ETD
- PLATE 66 DEFL
* plate 55 DEFl
$\times$ PLATE 44 DEFL

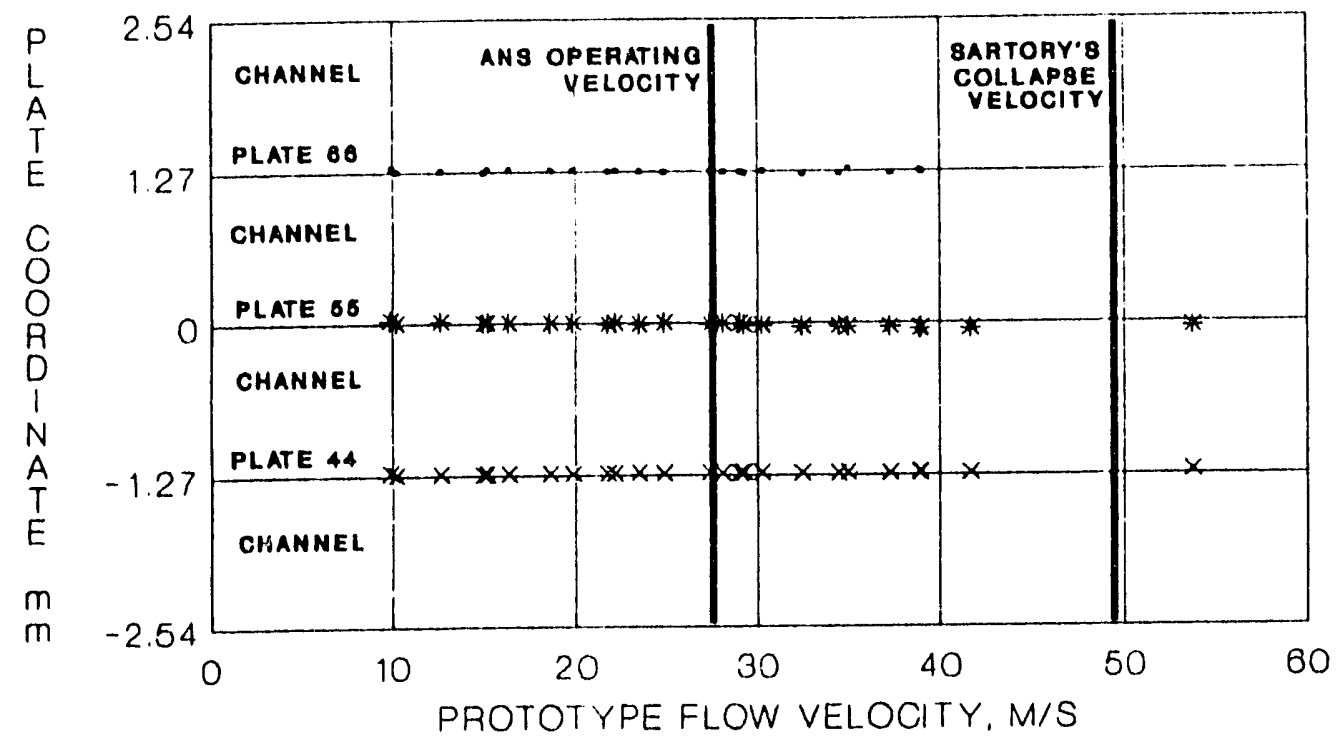

DATA TAKEN APRIL 1992

Fig. 18. Maximum deflection of lower element plates at exit. 
ORNL.DWO 93-2813 ETD

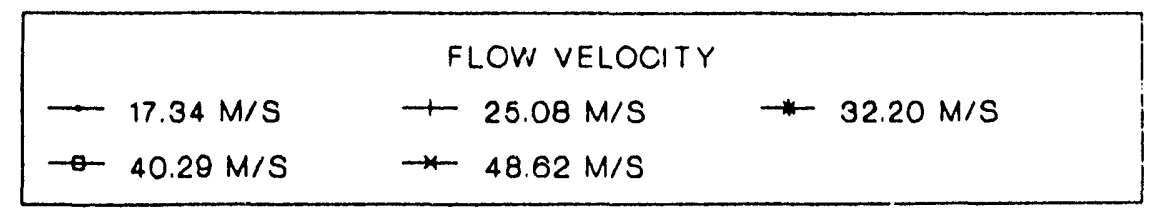

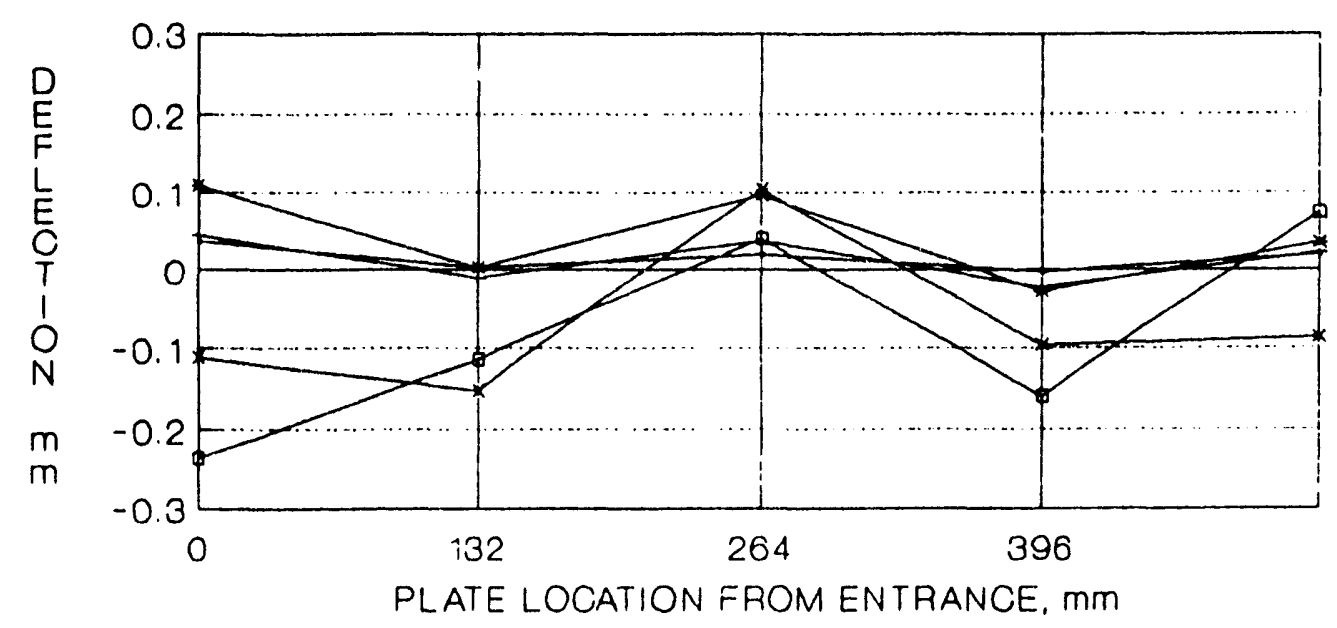

DATA TAKEN NOV 1991

Fig. 19. Maximum deflection of upper element plate 4 vs axial position.

ORNL. DWO 93.2914 ETD

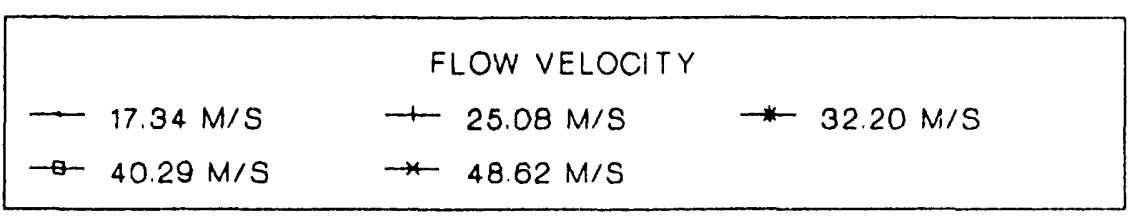

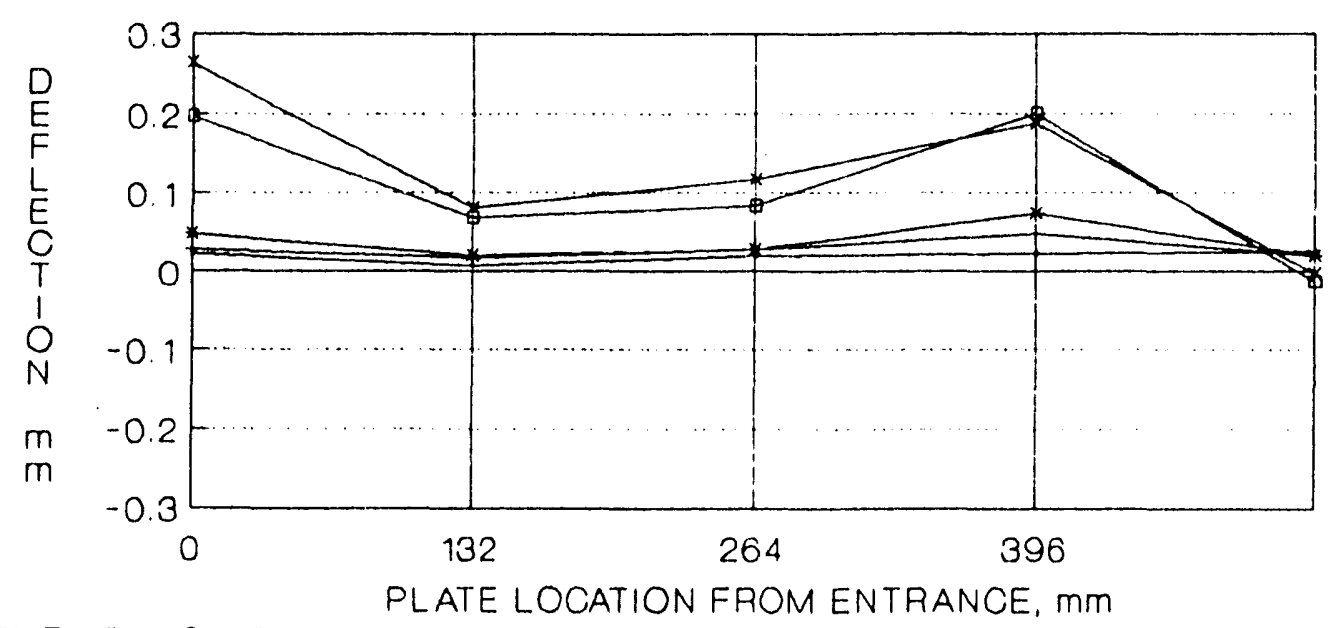

DATA TAKEN NOV 1991

Fig. 20. Maximum deflection of upper element plate $6 \mathrm{vs}$ axial position. 
ORNL.DWO 93.2915 ETD

\begin{tabular}{|c|c|c|}
\hline \multicolumn{3}{|c|}{ FLOW VELOCITY } \\
\hline$\rightarrow 17.34 \mathrm{M} / \mathrm{S}$ & $+25.08 \mathrm{M} / \mathrm{S}$ & * $32.20 \mathrm{M} / \mathrm{s}$ \\
\hline$\rightarrow \quad 40.29 \mathrm{M} / \mathrm{S}$ & * $48.62 \mathrm{M} / \mathrm{S}$ & \\
\hline
\end{tabular}

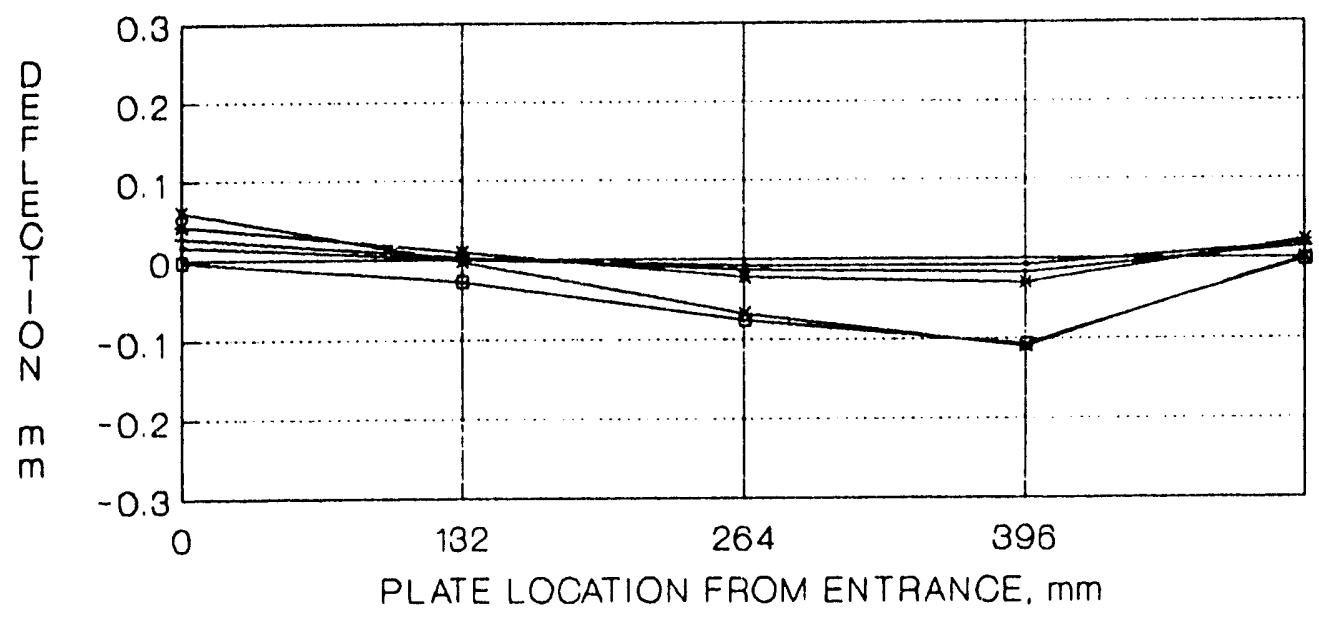

DATA TAKEN NOV 1991

Fig. 21. Maximum deflection of upper element plate $5 \mathrm{vs}$ axial position.

ORNL.DWG 93-2916 ETD

\begin{tabular}{|c|c|c|c|c|c|}
\hline \multicolumn{6}{|c|}{ FLOW VELOCITY } \\
\hline$\longrightarrow$ & $21.62 \mathrm{M} / \mathrm{S}$ & $\rightarrow$ & $27.28 \mathrm{M} / \mathrm{S}$ & $\rightarrow-$ & $30.21 \mathrm{M} / \mathrm{S}$ \\
\hline$\rightarrow$ & $34.94 \mathrm{M} / \mathrm{S}$ & $\rightarrow$ & $38.89 \mathrm{M} / \mathrm{S}$ & $\rightarrow$ & $41.82 \mathrm{M} / \mathrm{S}$ \\
\hline
\end{tabular}

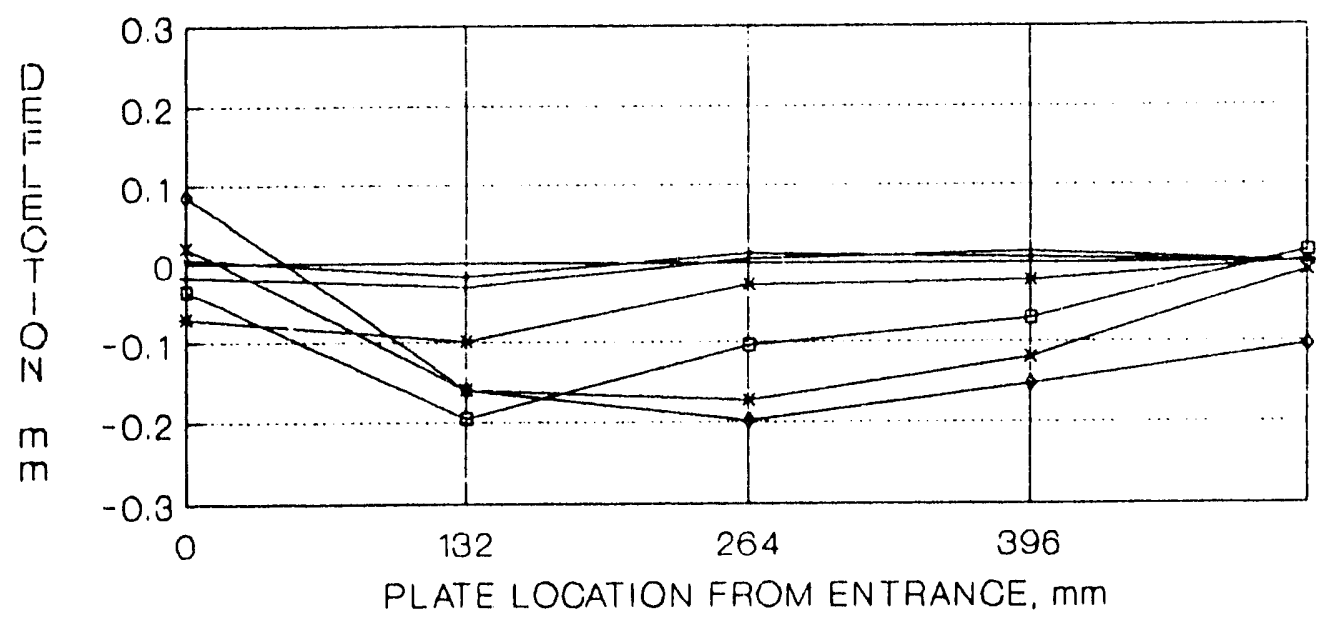

DATA TAKEN APRIL 1992

Fig. 22. Maximum deflection of lower element plate $66 \mathrm{vs}$ axial position. 
ORNL.DWO 03.2917 ETD
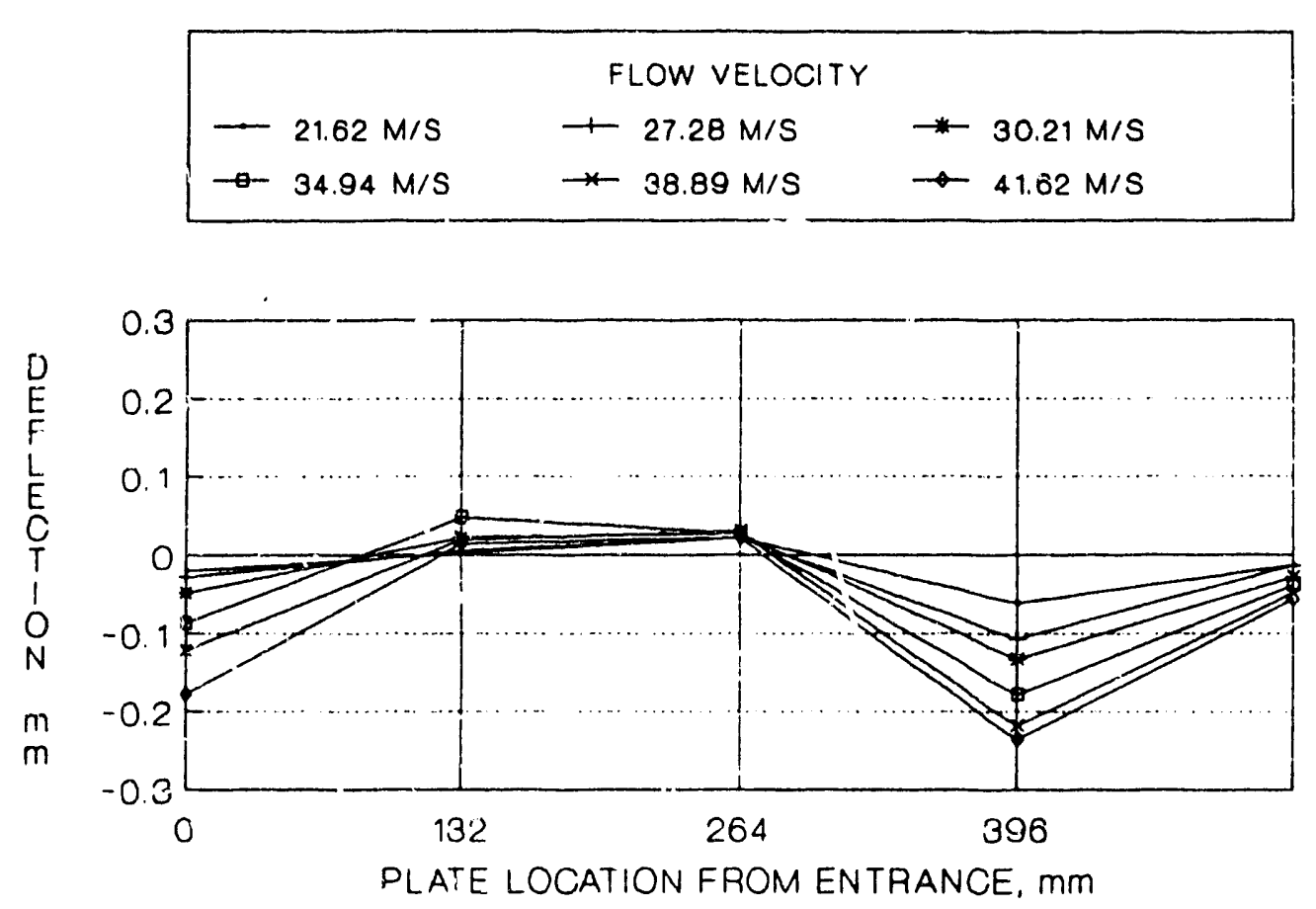

DATA TAKEN APRIL 1932

Fig. 23. Maximum deflection of lower element plate 55 vs axial prsition.

OANL.DWO 93-2918 ETD
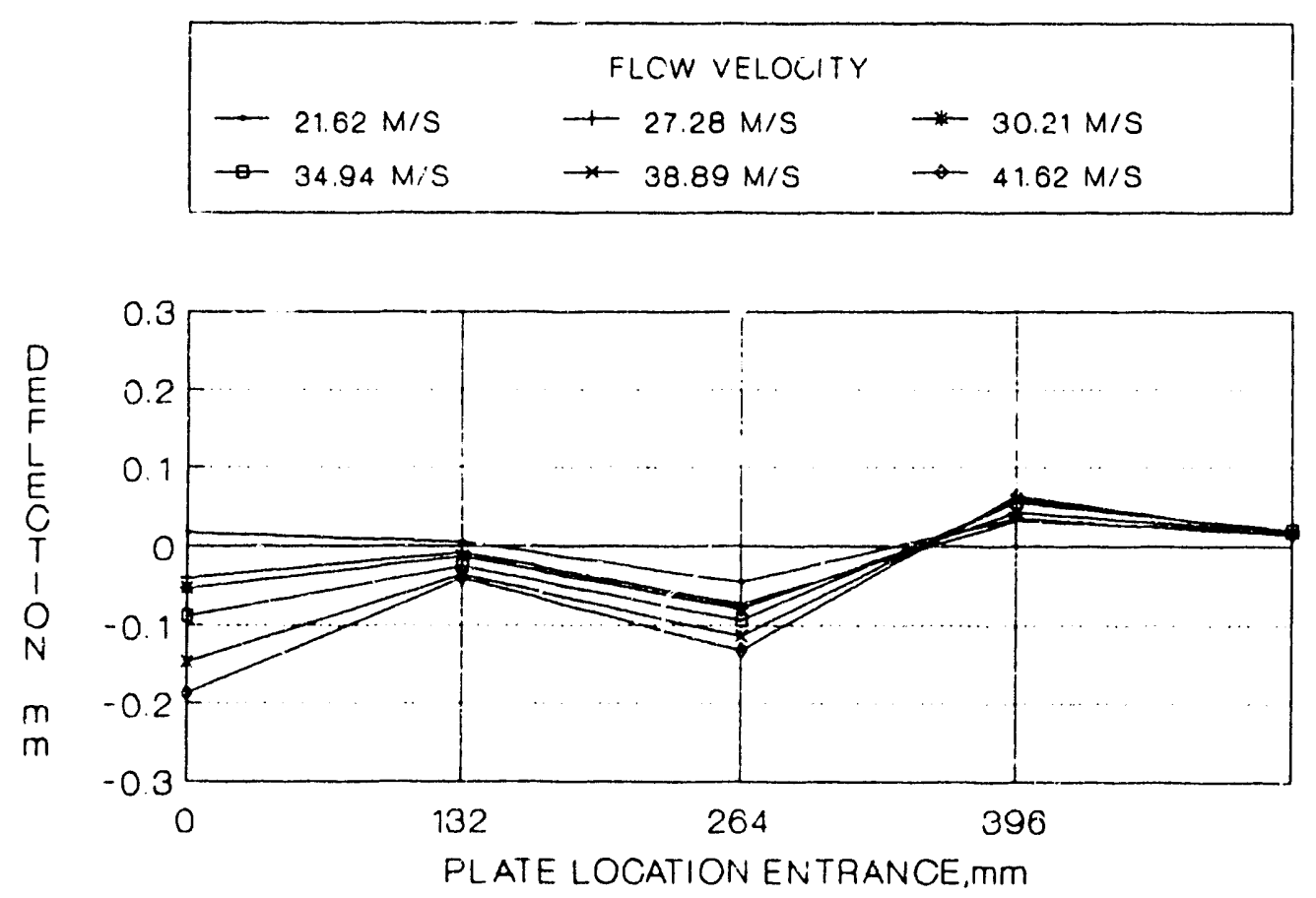

DATA TAKEN APRIL 1982

Fig. 24. Maximum deflection of lower element plate 44 vs axial position. 
ORNL.DWO 93-2919ET I

PLT.4 DEFL + PLT.4 PRESS $*$ PLT.6 DEFL
PLT.6 PRESS $\times$ PLT.5 DEFL

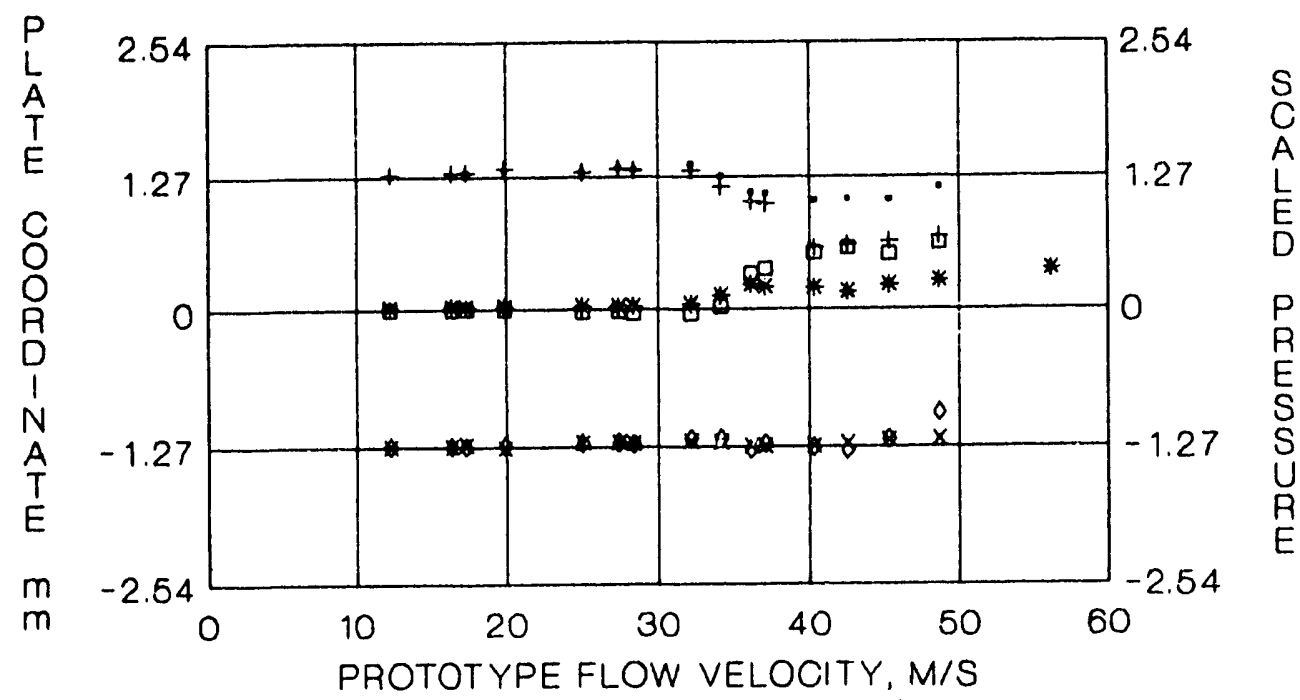

DATA TAKEN NOV 1991

Fig. 25. Maximum deflection and differential pressure on upper element plates at entrance.

ORNL.DWG 93.2920 ETD

- PLT 4 DEFL + PLT 4 PRESS * PLT 6 DEFL

- PLT 6 PRESS $\times$ PLT 5 DEFL $\triangle$ PLT 5 PFESS

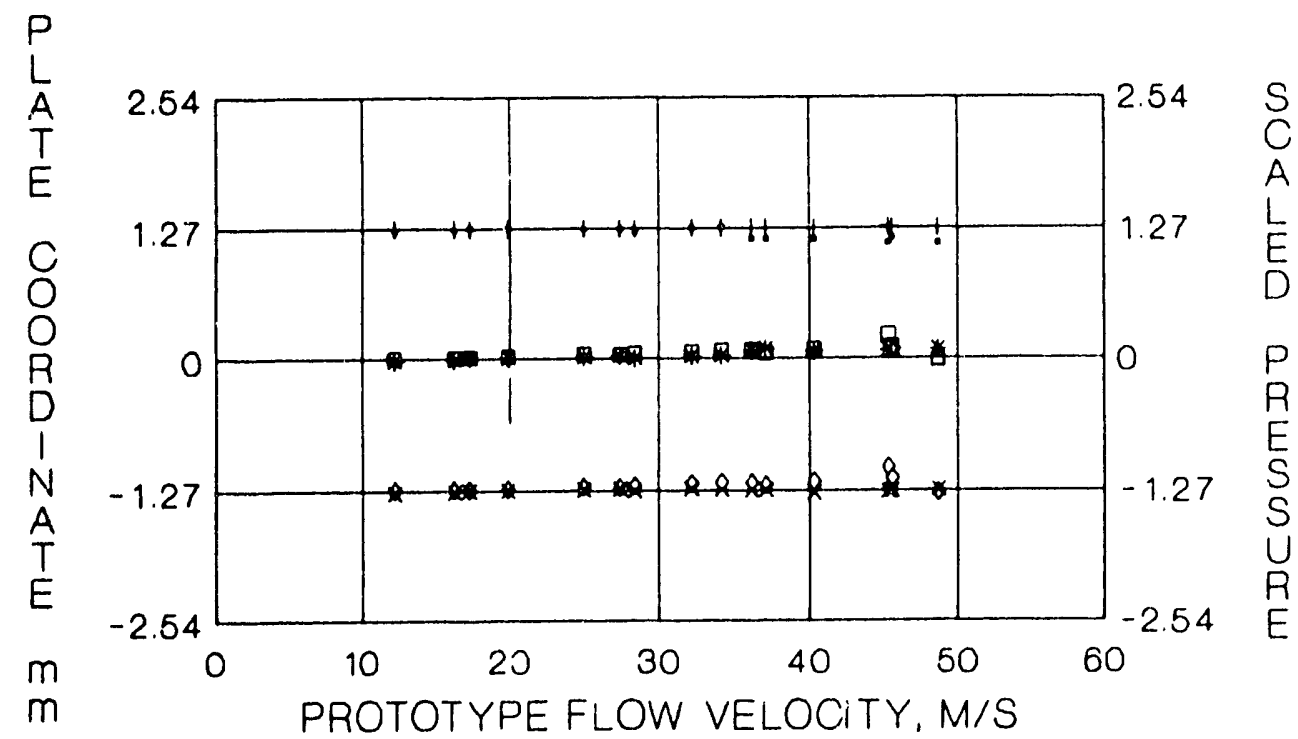

DATA TAKEN NOV 1901

Fig. 26. Maximum deflection and differential pressure on upper element plates at quarier point. 
ORNL.OWG 93-2921 ETD

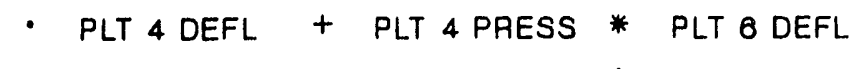

$\square$ PLT 6 PRESS $\times$ PLT 6 DEFL $\triangle$ PLT 5 PRESS

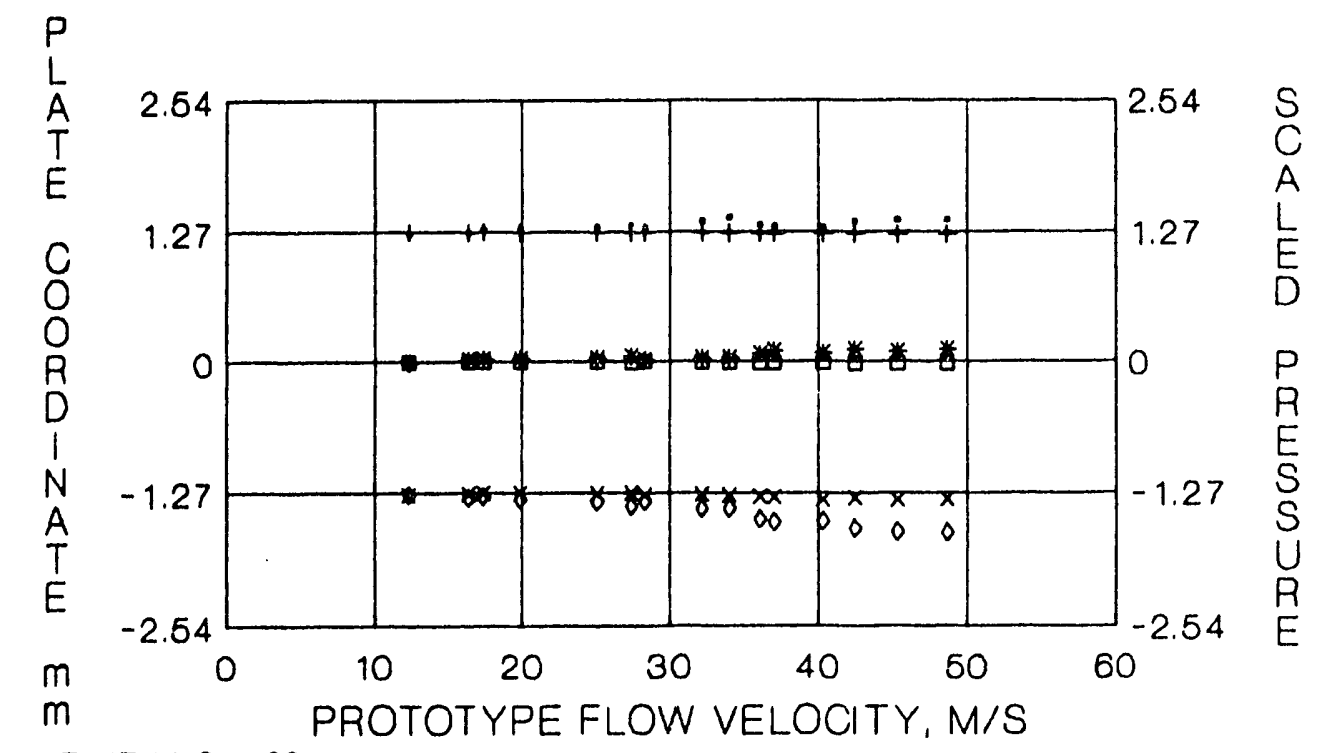

DATA TAKEN NOV 1801

Fig. 27. Maximum deflection and differential pressure on upper element plates at mid-length.

OANL.DWO $93-2922$ ETD
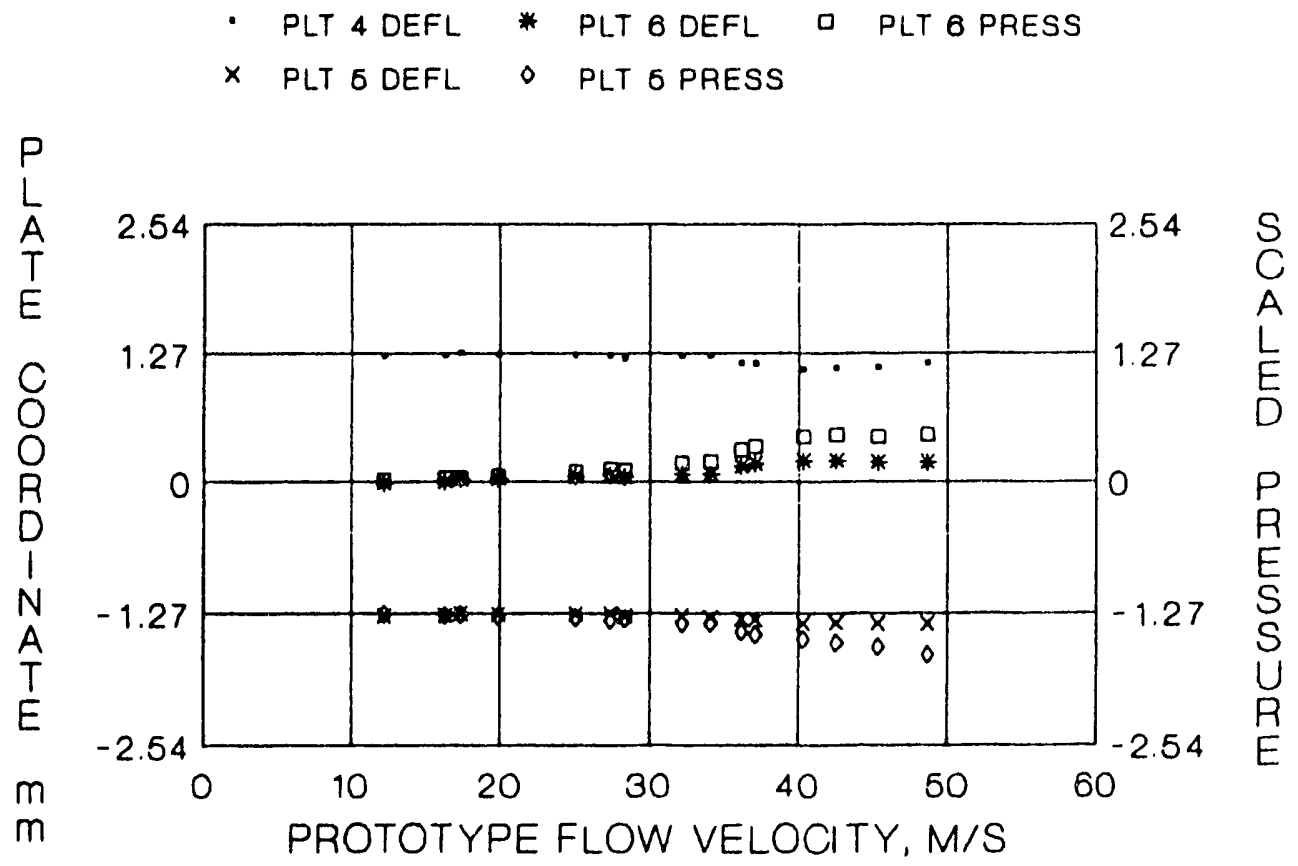

DATA TAKEN NOV 1991

Fig. 28. Maximum deflection and differential pressure on upper element plates at three-quarter point. 
OANL.OWO 93-2923 ETO

- plate 4 defl + Plate 4 press* plate 6 defl

- plate 6 paess plate 5 defl $\diamond$ plate 5 press

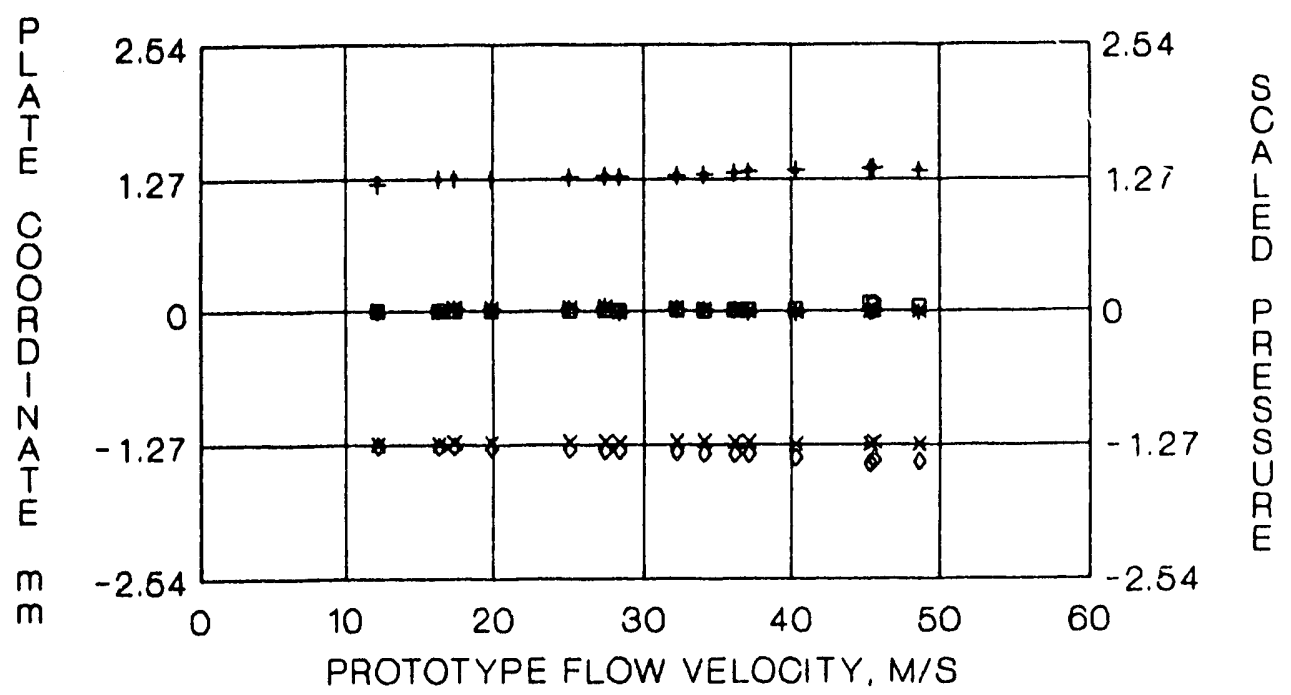

DATA TAKEN NOV 1991

Fig. 29. Maximum deflection and differential pressure on upper element plates at exit.

ORNL.DWO 93-2924 ETD

- PLT 66 DEFL + PLT 66 PRESS * PLT 55 DEFL

- PLT 55 PRESS $\times$ PLT 44 DEFL $\diamond$ PLT 44 PRESS

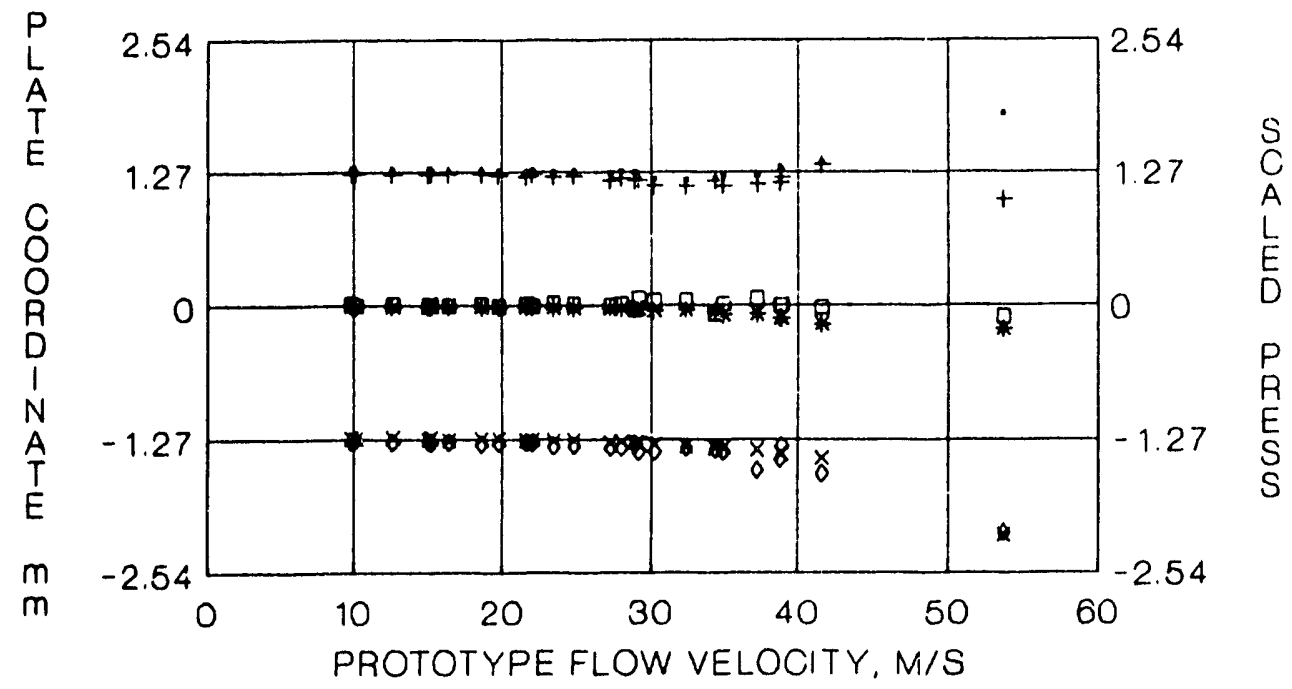

DATA TAKEN APRIL 1992

Fig. 30. Maximum deflection and differential pressure on lower element plates at entrance. 
OANL.DWG 93.2925 ETD

- PLT 66 DEFL + PLT 66 PRESS * PLT 55 DEFL

- PLT 55 PRESS $\times$ PLT 44 DEFL $\triangle$ PLT 44 PRESS

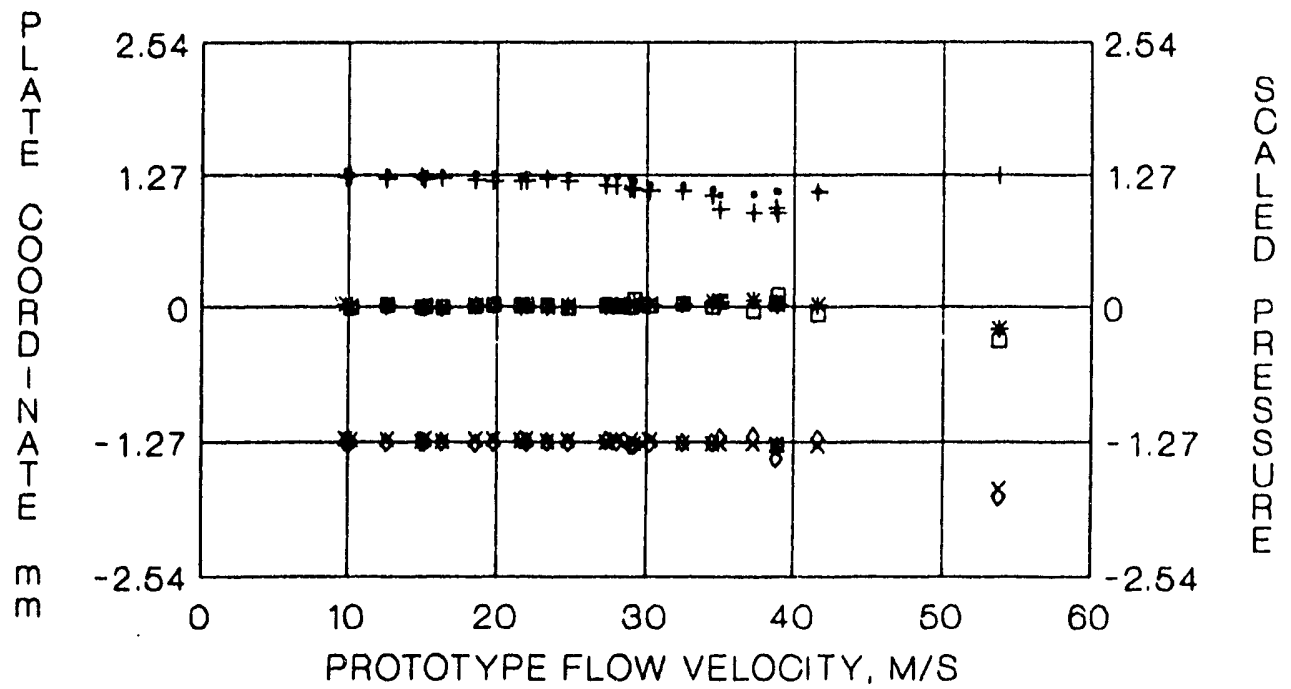

DATA TAKEN APRIL 1982

Fig. 31. Maximum deflection and differential pressure on lower element plates at quarter point.

ORNL.DWG 93.2926 ETD

- PLT 66 DEFL + PLT 66 PRESS * PLT 55 DEFL

- PLT 55 PRESS $\times$ PLT 44 DEFL $\triangle$ PLT 44 PRESS

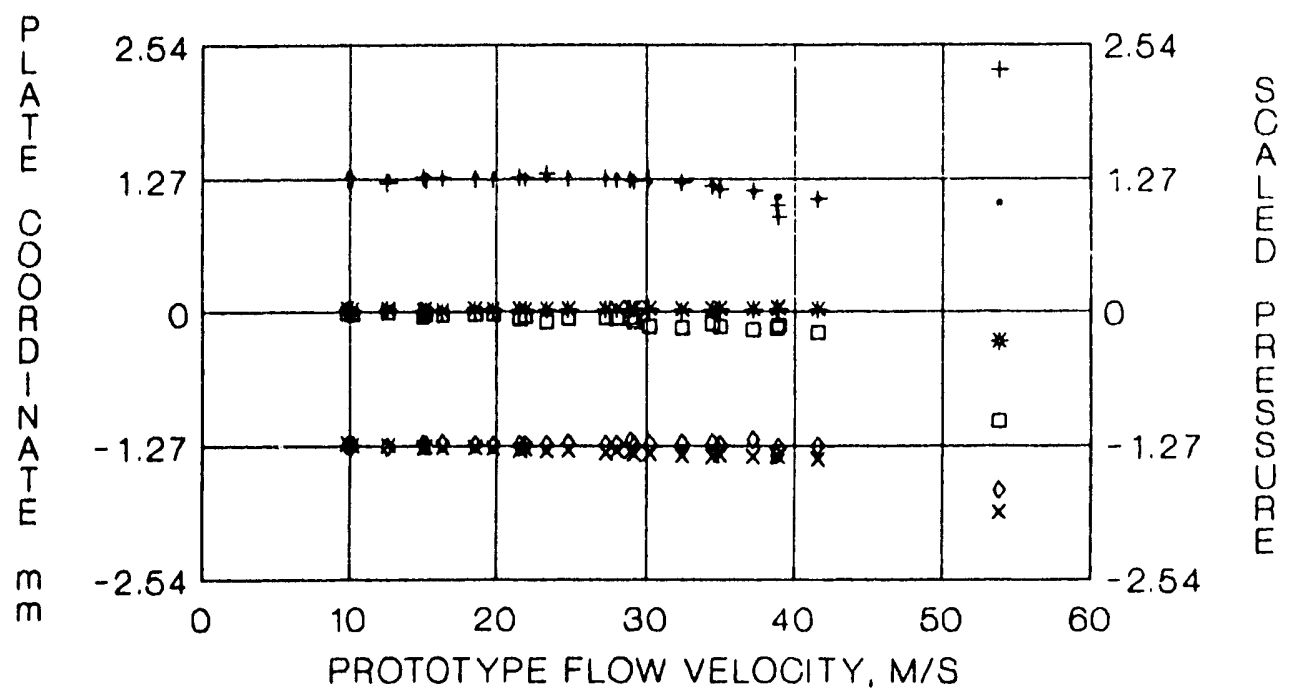

DATA TAKEN APRIL 1982

Fig. 32. Maximum deflection and differential pressure on lower element plates at mid-length. 
ORNL.DWG 93-2927 ETD
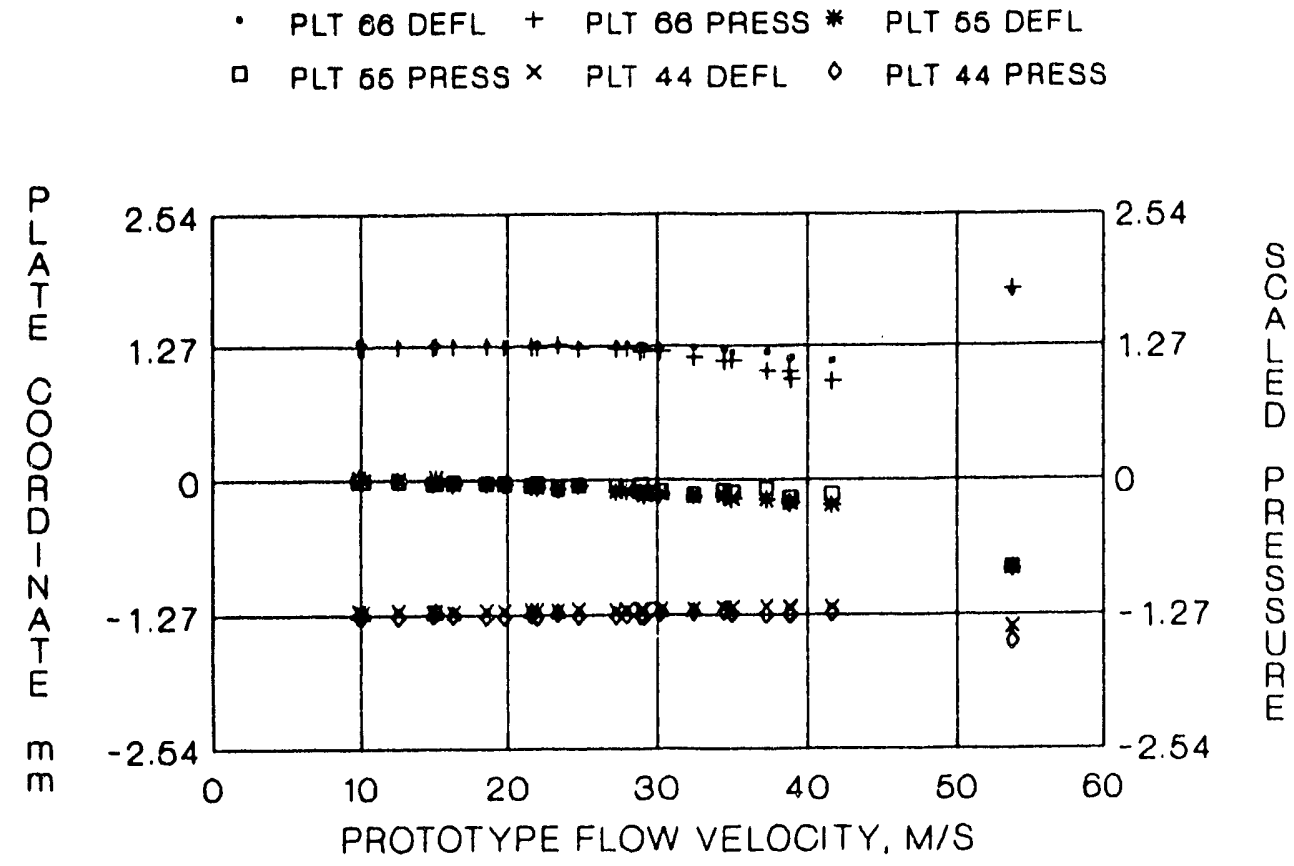

DATA TAKEN APRIL 1982

Fig. 33. Maximum deflection and differential pressure on lower element plates at three-quarter point.

OHNI. DWG 93.2928 ETD

- PLT 66 DEFL + PLT 66 PRESS * PLT 55 DEFL

- PLT 55 PRESS $\times$ PLT 44 DEFL $\bigcirc$ PLT 44 PRESS

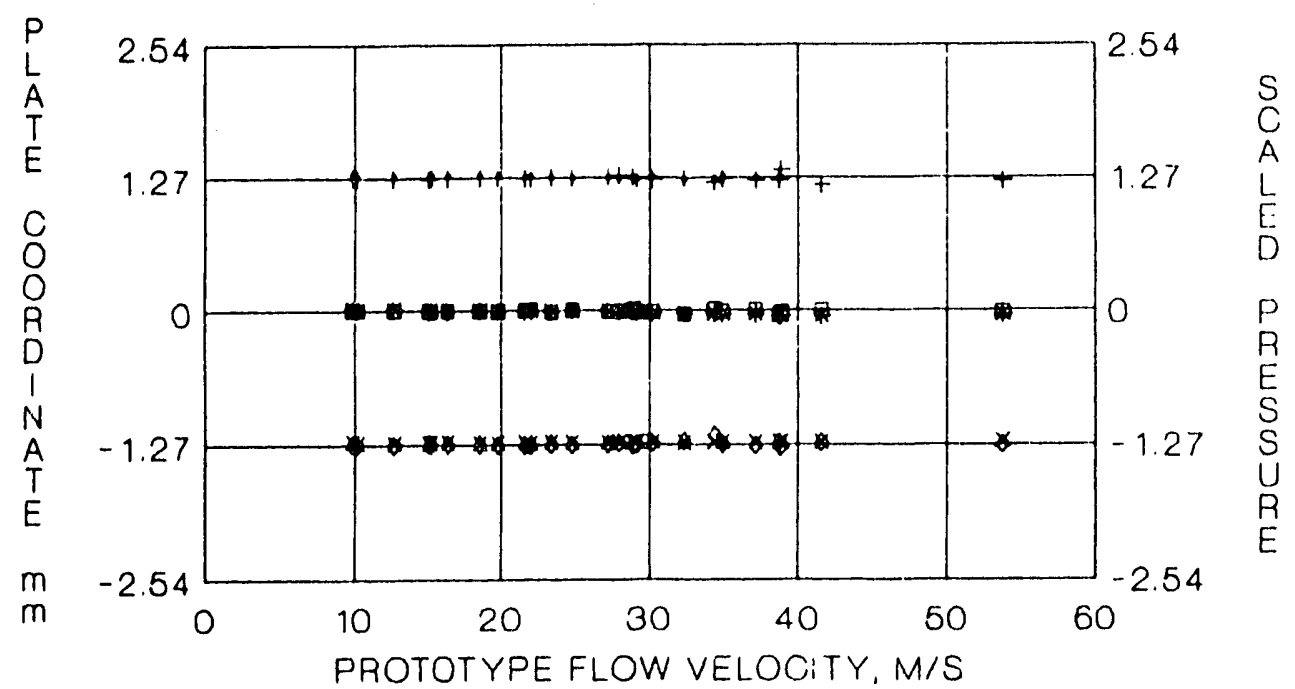

DATA TAKEN APRIL 1982

Fig. 34. Maximum deflection and differential pressure on lower element plates at exit. 


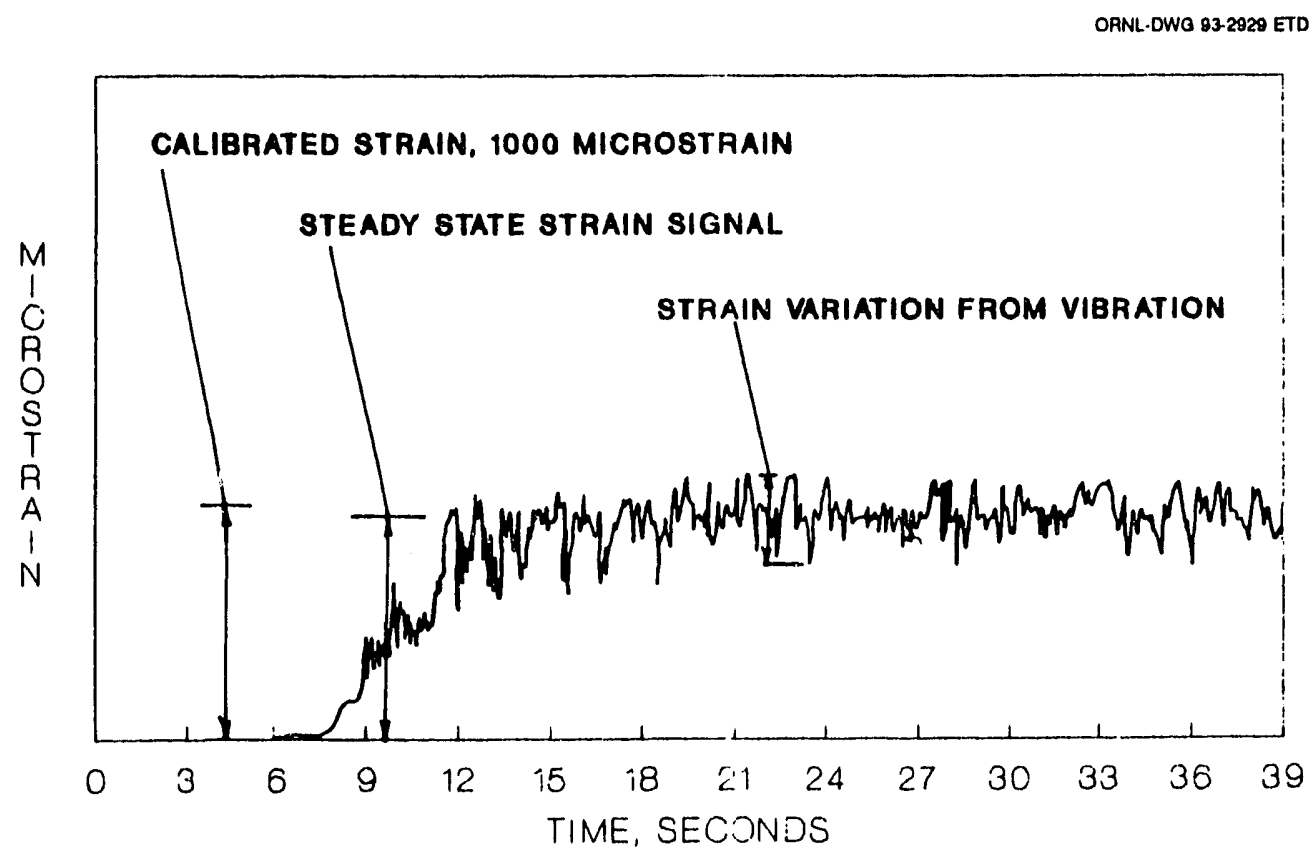

DATA TAKEN NOV 1991

Fig. 35. Entrance strain gage response vs time of upper element plate 6 at $36.1 \mathrm{~m} / \mathrm{s}$ flow velocity.

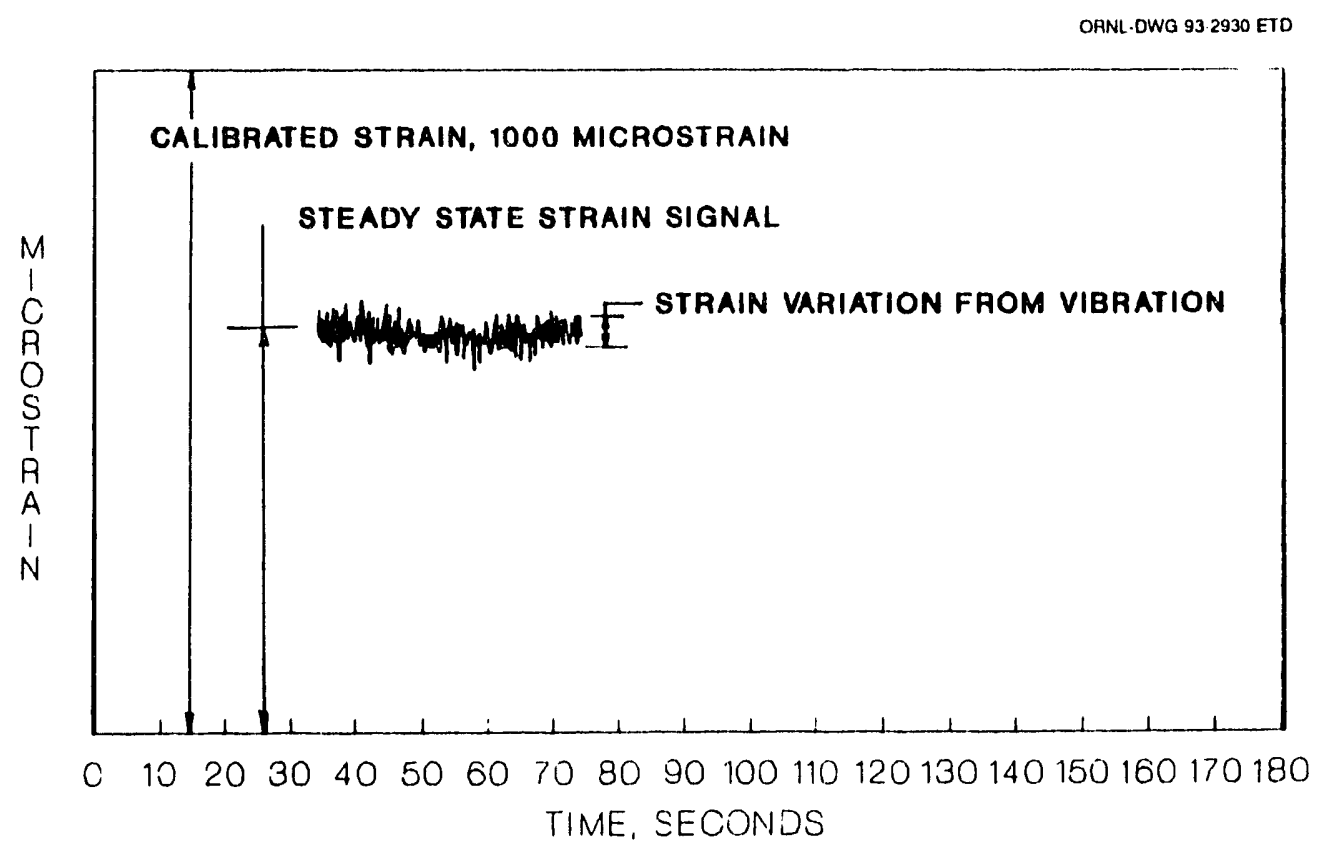

DATA TAKEN APA 1992

Fig. 36. Entrance strain gage response vs time of lower element plate 55 at $53.7 \mathrm{~m} / \mathrm{s}$ flow velocity. 


\section{DISCUSSION OF DATA}

This experimental program had two objectives: (1) to observe the potential for plate instability because of the closely spaced plates and high coolant velocities and (2) to determine the maximum plate deflection as a function of coolant velocity. The plate deflection curves shown in Figs. 9-18 indicate that essentially the plate deflection increases as the flow velocity increases. The curves for plate deflection and pressure difference across a plate versus flow velocity (Figs. 25-34) suggest that the plate deflection and pressure difference are directly related. This bounded structural response is not characteristic of an unstable response. Gwaltney and Luttrell 10 extended the collapse theory as proposed by Miller 6 to involute plates. Sartory ${ }^{11}$ developed Miller's theory further to include friction effects and inletoutlet effects. The results of these analyses are shown superimposed on the experimental data in Figs. 25-34. The data do not show a sudden shift or rapid increase in the entrance deflection as predicted by the theory. Rather, the data (Figs. 25-34) show a somewhat smooth response of the deflection to the pressure difference across the plate. The maximum deflection point occurs at different cross sections, such as the entrance, the half, and the three-quarter section (Figs. 19-24), while the theory always predicted maximum deflection at the entrance. There was no experimental evidence indicating a plate collapse. It can be observed that deflection is a nonlinear function of tlow velocity (Figs. 9-18). This nonlinear behavior is predictable since the pressure difference is the driving mechanism and is a nonlinear function of the flow velocity. Figure 25 illustrates that according to the pressure difference the plates should touch, but the strain gage data show that the plates do not touch. This suggests that the fluid in the channel inhibits the plate deflection as the channel becomes small by some means other than hy changing its pressure. During an initial test of the upper plates, significant plate deflections in the entrance region were observed at a flow velocity of $40 \mathrm{~m} / \mathrm{s}$, and at a $56-\mathrm{m} / \mathrm{s}$ flow velocity large plate deflections were observed such that adjacent plates probably touched. The data for the entrance deflection versus flow velocity for this initial test are shown in Fig. 37. This value was close to Sartory's collapse velocity. In continuing the test, the test section was disassembled to repair a leak, and at this time 3-mm radii were made into the shoulders of the entrance and exit channel of the flow straightener. The purpose of the radii was to alleviate any misalignment of the flow straightener with the test plates. In subsequent tests with the "smoothed" straightener, plate deflections (Fig. 9) were reduced by hall when compared with earlier tests (Fig. 37) and are considered more typical. This dilference in results between the initial test and the smoothed test gave an indication of how sensitive plate response is to llow alignment. The data reported in this paper, except for those in Fig. 37, were obtained with the smoothed flow straightener. 
OANL.DWG 93.2931 ETD

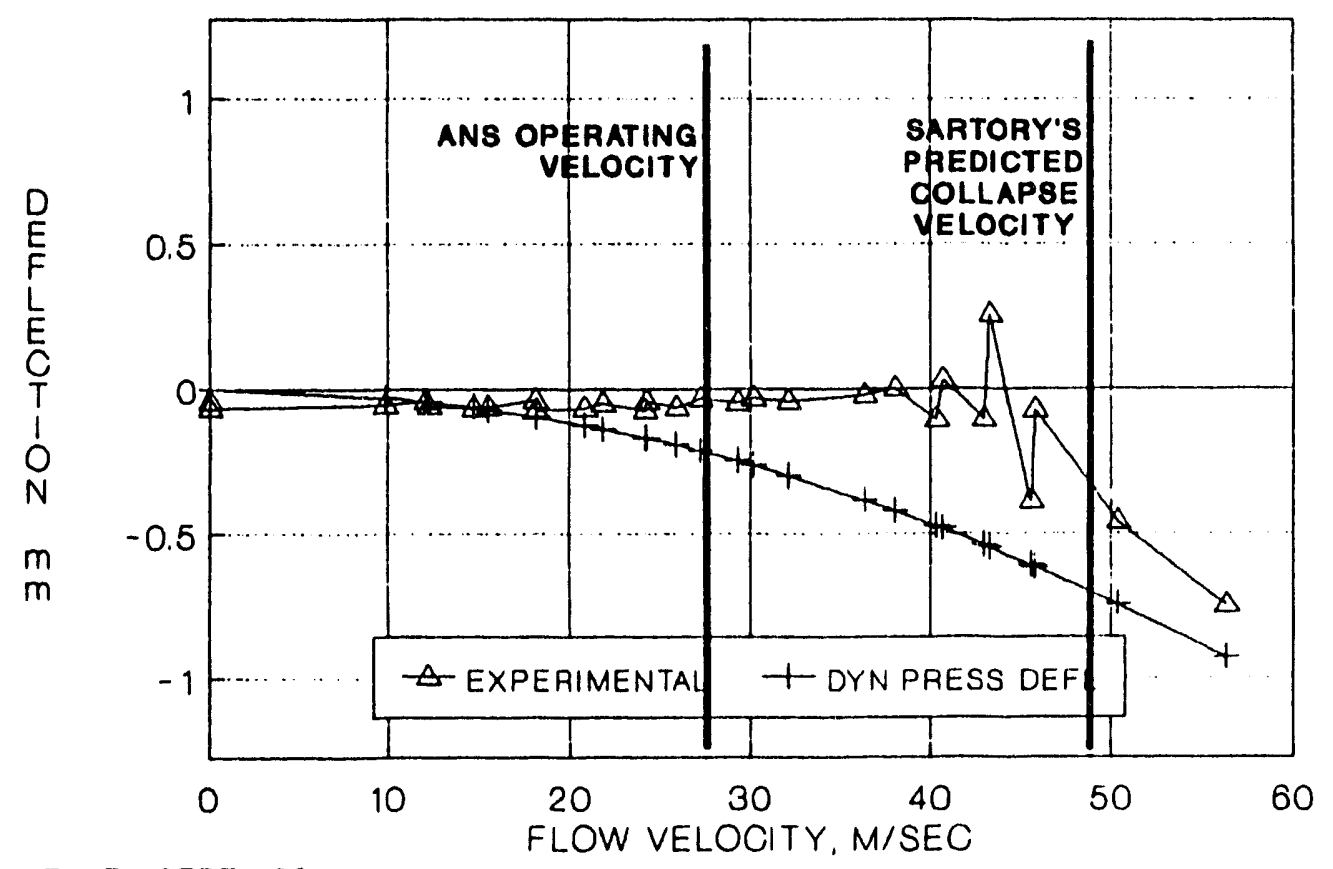

DATA TAKEN SEPT, 1991

Fig. 37. Maximum deflection of upper element plate 6 at entrance during the initial test with unsmoothed transition from flow straightener.

A flow experiment was also performed on a single HFIR involute plate, which has dimensions that are similar to the ANS plate. This test section also had very smooth flow entering the plates. The results of this test (Fig. 38) were similar to the results of the ANS involute plates shown in Fig. 9-i.e., continuous increase in plate deflection with increasing flow velocity. The lack of a sudden or rapid change in plate deflection at the entrance and at a specific critical flow velocity was evidence that conditions for plate collapse were not present.

Given the evidence of the experimental data, it appears that the classical assumptions used in modeling the complicated hydraulic-structural response of the plates may not be valid in a real system. For example, the Miller model assumes a constant mass flow in each channel that remains constant even as a channel begins to close up; in a real system this may not occur. An interesting alternative to the constant mass flow assumption is to assume parallel flow with different mass flow. As this alternative demonstrates, the results are very dependent on the assumed model. In a consideration of parallel flow, the flow channels are modeled as pipes with the same hydraulic diameter so that friction data of pipes can he used. In this analysis one channel height is assumed smaller and an adjacent channel height is assumed larger than the nominal dimension, as might occur from tolerances in assembly. The solution notes that the larger channel has more mass flow and a higher flow velocity than the smaller channel. In addition, the model predicts a 


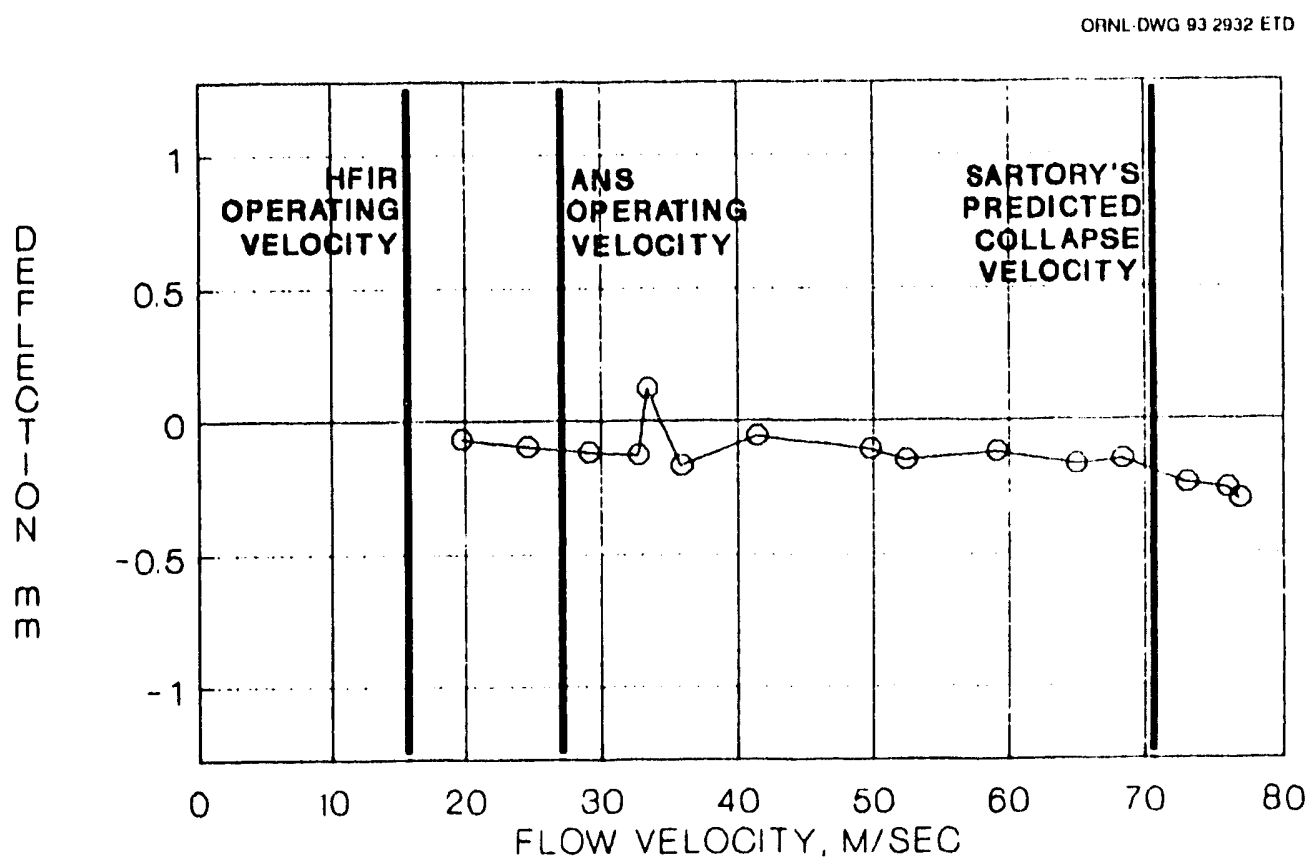

DATA TAKEN MAR. 1980

Fig. 38. Maximum deflection at entrance of single epoxy HFIR plate test.

stable flow in contrast to the unstable flow with a constant mass llow assumption. The pressure difference in this parallel flow model across the plate separating the large (1) channel from the small (s) channel is

$$
\Delta p=\frac{V_{1}^{2}-v_{\mathrm{s}}^{2}}{2} \rho_{\mathrm{r}}
$$

This difference tends to make the small channel larger and the larger channel smaller, which is a stable response. While the magnitude of the pressure difference was similar to experimental values, there are assumptions that make drawing numerical values from this analysis questionable. It does, however, offer a mechanism for the stable llow observed in the experiments.

The second purpose for conducting the experiments was to determine the maximum plate deflection as a function of coolant velocity. The results, scaled to the prototype deflections through model theory, have been illustrated in Figs. 9-18. Attention is called to the ANS operating coolant velocity $(27.4 \mathrm{~m} / \mathrm{s}){ }^{*}$ where the deflections are small.

Finally, it was proposed hy Swinson and Yahr ${ }^{12}$ to use the dynamic (stagnation) pressure as the plate-loading mechanism for design purposes to obtain yuantitative values for the plate deflection versus flow velocity. Sample results of this compartison are shown in Figs. 39-42.

*'The operating flow velocity for the ANS has been revised $102.5 \mathrm{~m} / \mathrm{s}$. 
OANL.DWO 93-2933 ETD
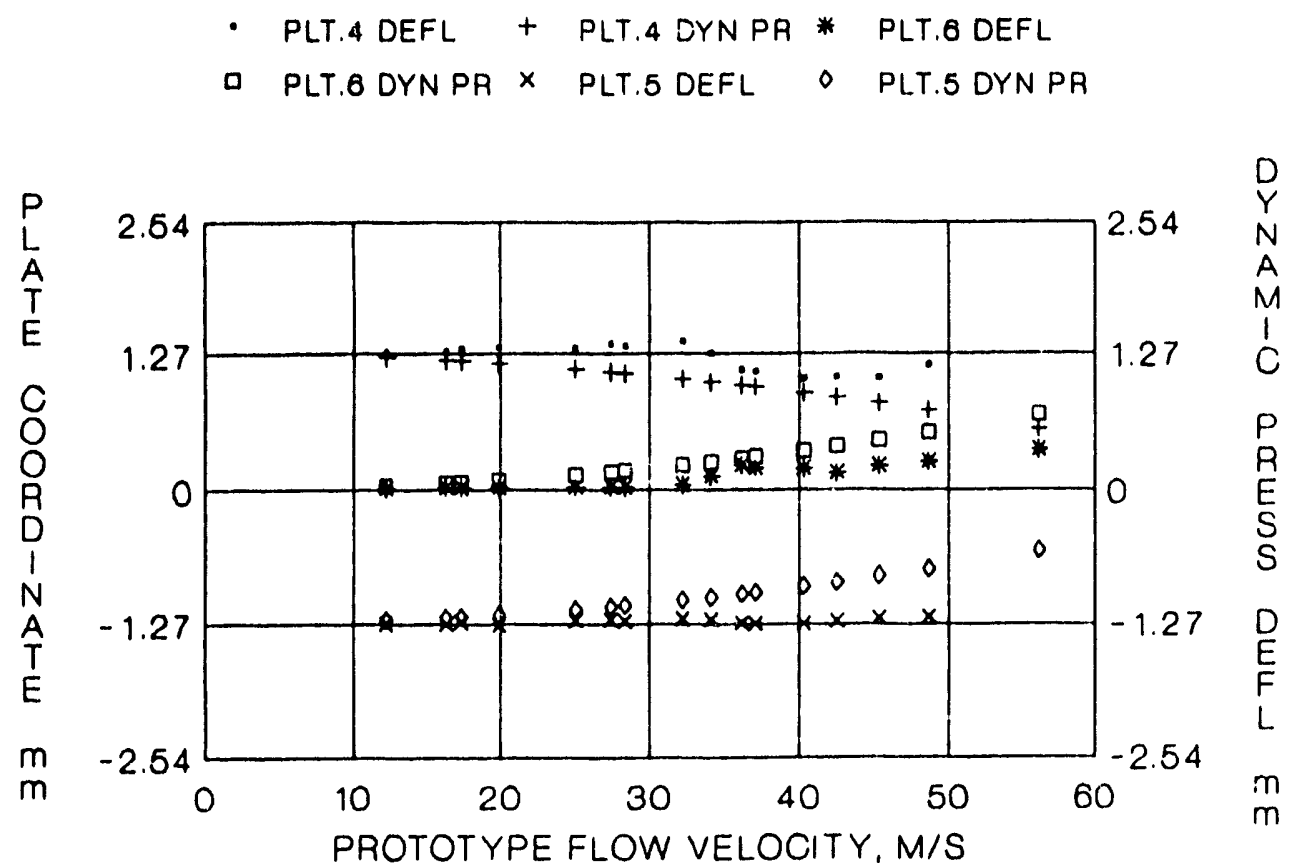

DATA TAKEN NOV 1991

Fig. 39. Comparison of dynamic pressure predictions with measured deflections at entrance for upper element plates.

ORNL. DWG 93.2934 ETD

- PLT 4 DEFL + PLT 4 DYNPR * PLT 6 DEFL

- PLT 6 DYNPR $\times$ PLT 5 DEFL $\triangle$ PLT 5 DYNPA

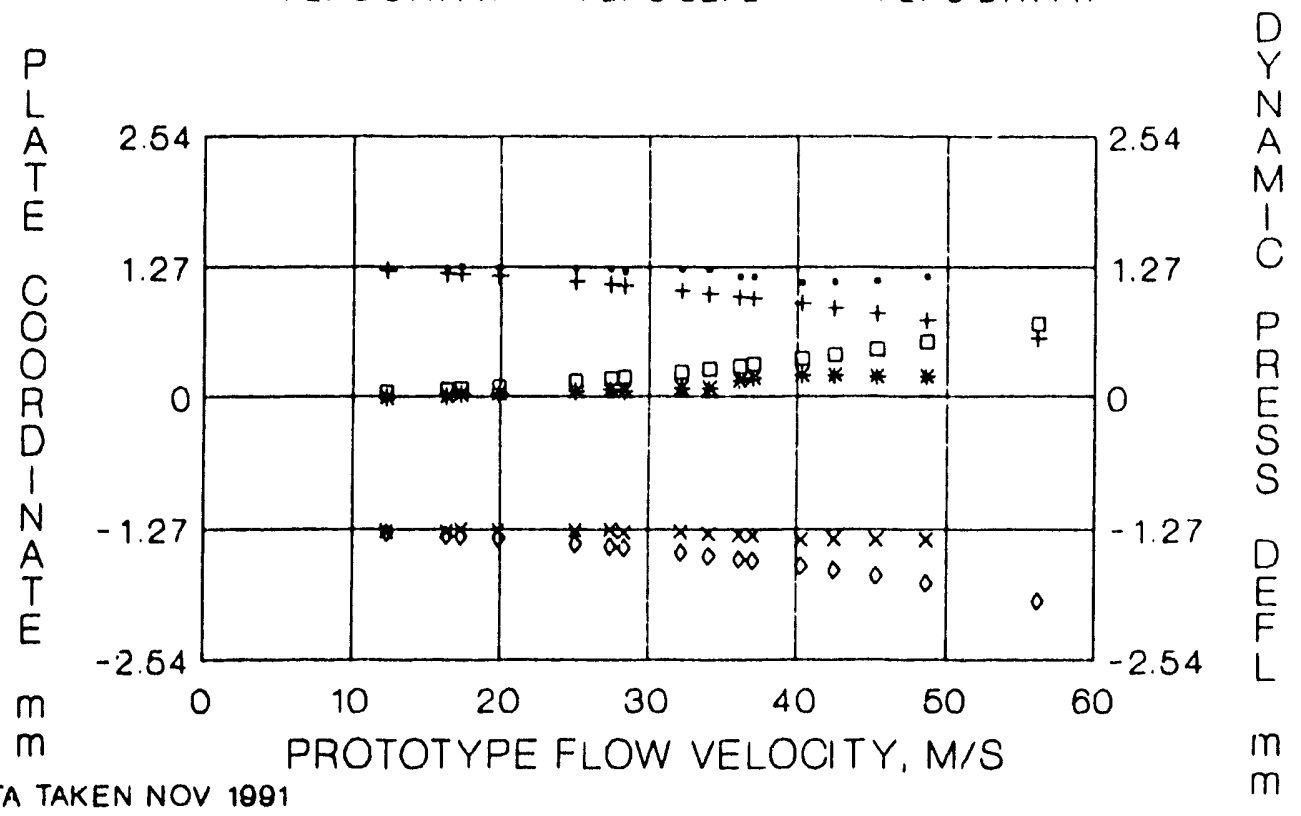

Fig. 40. Comparison of dynamic pressure predictions with measured deflections at threequarter point for upper element plates. 
ORNL.DWG 93.2935 ETD

- PLT 66 DEFL + PLT 66 DYNPR* PLT 55 DEFL

- PLT 65 DYN PRX PLT 44 DEFL O PLT 44 DYN PR

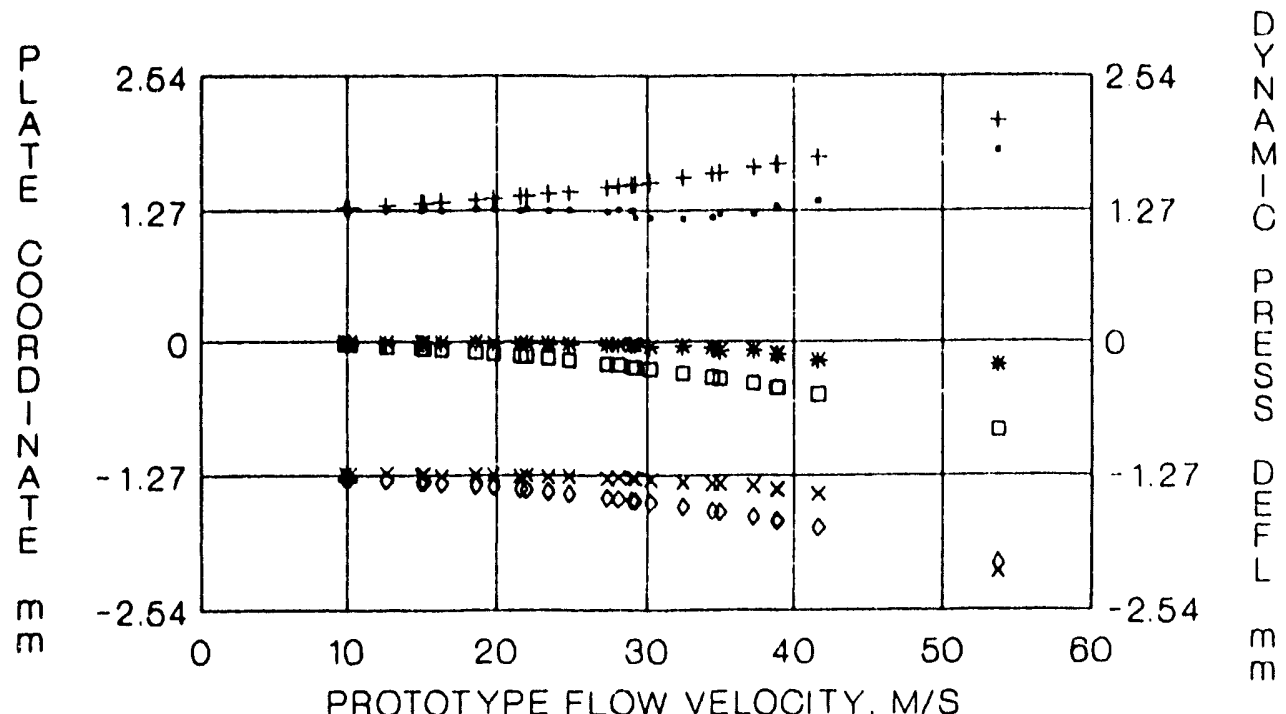

DATA TAKEN APAIL 1982

Fig. 41. Comparison of dynamic pressure predictions with measured deflections at entrance for lower element plates.

ORNL. DWO 93.2936 E1D

- PLT 66 DEFL + PLT 66 OYNPR* PLT 55 DEFL

- PLT 65 DYN PAX PLT 44 LEFL O PLT 44 CYNPR

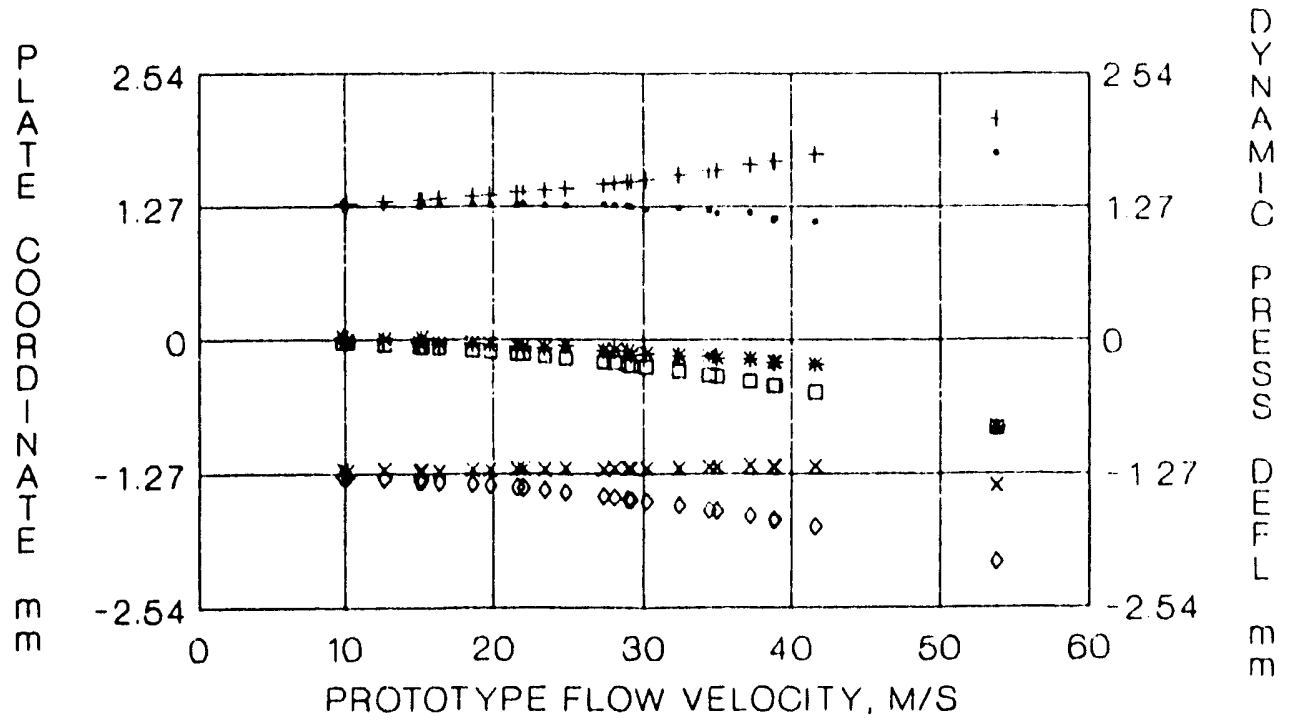

DATA TAKEN APRIL 1992

Fig. 42. Comparison of dynamic pressure predictions with measured deflections at threequarter for lower element plates. 
It can be observed that the result is an upper bound and that the trend of plate deflection versus flow velocity is similar. Note that the initial test on the upper plate model, which had some misalignınent with the flow straightener, had deflection magnitudes similar to and bounded by the dynamic pressure deflections (Fig. 37). Unbounded deflection is typical of unstable systems. The fact that all deflections in these experiments are bounded by the dynamic pressure deflection suggests that instabilities are not present in the plates for the velocity range examined. Use of this dynamic pressure technique to get an upper-bound estimate of the plate response would be helpful to a designer in setting limits on plate deformations. This technique would also be helpful in estimating thermal hydraulic effects, since heat transfer depends on the channel dimensions. 


\section{CONCLUSIONS}

Tests on five-epoxy-plate models of the ANS fuel elements demonstrate that the instability predicted by Miller's theory does not occur. Plate deflections were very small at the prototypic ANS conditions. Plate deflections were observed at high-flow velocities beyond the velocities expected in the ANS. The observed velocities were hounded by predictions based on the dynamic pressure. It is recommended that the dynamic pressure method be used as a conservative estimate of flow-induced plate deflection.

These tests showed that any disturbance of uniform flow entering the channels surrounding the fuel plates has a pronounced effect on observed plate deflections. Future tests are planned on complete dummy fuel elements under prototype conditions to ensure proper performance in the ANS.

Vibrations were observed at certain llow velocities. Tests on aluminum plates must be performed to determine whether such vibrations will occur in the fuel plates within the operating range of the ANS.

Additional tests on epoxy plate models of hoth the upper and lower fuel elements will be done to corroborate these results. 


\section{RERERENCES}

1. C. D. West, "Overview of the ANS Project," Trans. Am. Nucl. Soc. 57, 288-89 (1988).

2. R. M. Harrington, "Designing for Safety in the Conceptual Design of the Advanced Neutron Source," Nuclear Safety 32 (April-June 1991).

3. W. K. Stromquist and O. Sisman, High Flux Reactor Assemblies Vibration and Water Flow, ORNL-50, Oak Ridge National Laboratory, June 1948.

4. R. G. Beck, E. S. Brown, and J. H. Rainwater, ETR Core Hydraulics, USAEC, IDO-16464, Phillips Petroleum Company, Idaho Operations Office, September 1958.

5. R. G. Beck, Hydraulics of Modified Fuel Elements for ETR, USAEC, IDO-16465, Phillips Petroleum Company, Idaho Operations Office, November 7, 1958.

6. D. R. Miller, "Critical Flow Velocities for Collapse of Reactor Parallel Plate Fuel Assemblies," Trans. ASME 82, 83 (196()).

7. R. D. Groninger and J. J. Kanc, "Flow-Induced Deflections of Parallel Flat Plates," Nucl. Sci. Eng. 16. 218 (1963).

8. G. E. Smissaert, "Static and Dynamic Hydro-elastic Instabilities in MTR-Type Fuel Elements. Part I. Introduction and Experimental Investigation," Nucl. Eng. Des. 7, 535-546 (1968).

9. W. L. Zabriskic. An Experimenaal Evaluation of the Critical Flow Velocity Formulas for Parallel Plate Assemblies, General Electric, Report 58GL297, Octnber 31, 1958.

10. R. C. Gwaltney and C. R. Luttre!!. "Critical Flow Velocity for Involute Farallel Fuel Plate Assemblies," Trans. Aam. Nucl. Soc. 57, 298 (1988).

11. W. K. Sartory, Analysis of Hydraulic Instability of ANS Involute Fuel Plates, ORNL TM-11580, Martin Marietta Energy Systems, Inc., Oak Ridge Natl. Lab., November 1991.

12. W. F. Swinson and G. T. Yahr, "Dynamic Pressure Approach to Analysis of Reactor Fuel Plate Stability," Trans. Am. Nucl. Soc. 61, 390(199()). 


\section{Appendix A MODEL THEORY}

The theory from dimensional analysis used in going from model steady state deflection to prototype steady state deflection considered the plate variables to be

$\delta$ deflection

E modulus of elasticity

$\mu \quad$ Poisson's ratio

L dimension parameter

and the fluid (water) variables to be

$\begin{array}{cl}V & \text { velocity } \\ \mu_{\mathrm{f}} & \text { viscosity } \\ \rho_{\mathrm{f}} & \text { density. }\end{array}$

The necessary dimensionless terms were

$$
\begin{aligned}
& \pi_{1}=\delta / L \\
& \pi_{2}=\mu \\
& \pi_{3}=V^{2} \rho_{\mathrm{f}} / \mathrm{E} \\
& \pi_{4}=\mu_{\mathrm{f}} V / \mathrm{EL} .
\end{aligned}
$$

The dimensionless term $\pi_{4}$, with fluid viscosit $;$, is related to the friction force in the direction of flow velocity; thus, its effect on the plate deflection in a direction perpendicular to the flow velocity is considered small. The dimensionless term $\pi_{2}$ is Poisson's ratio. In this case the prototype has a Poisson's ratio of 0.33 , while the model material has a ratio of 0.35 . From plate theory Poisson's ratio shows up as $\left(1-\mu^{2}\right)$, and the difference between using 0.33 and 0.35 is small. The dimensionless term $\pi_{1}$ for a full-scale model requires that

$$
\delta_{\mathrm{p}}(\text { prototype deflection })=\delta_{\mathrm{In}}(\text { model dellection }) \text {. }
$$

The dimensionless term $\pi_{3}$ requires that

$$
V_{\mathrm{p}}=V m \sqrt{E_{\mathrm{p}} / E_{\mathrm{m}}}
$$

and was used to scale the prototype velocity from the model velocity. 


\section{Appendix B \\ PRESSURE DROP}

Operating reports from HFIR give the pressure drop $\left(\Delta P_{\mathrm{L}}\right)$ through the plate length as $758.4 \mathrm{kPa}(110 \mathrm{psi})$ at $15.5 \mathrm{~m} / \mathrm{s}(51 \mathrm{ft} / \mathrm{s})$ flow velocity. The friction factor for one channel is estimated by relating it to an equivalent circular pipe so that available data can be utilized. Let

$$
D_{\mathrm{H}}=4 A / P_{\mathrm{w}}=\frac{4(1.27)(75.874575)}{2(1.27+75.874575)}=2.498 \mathrm{~mm}(0.0984 \text { in. }) \text {, }
$$

where

$D_{\mathrm{H}}=$ an equivalent pipe diameter,

$A=$ cross-sectional flow area,

$P_{\mathrm{W}}=$ the wetted perimeter.

Reynolds number for this equivalent diameter and velocity is

$$
R_{\mathrm{e}}=\frac{\rho_{\mathrm{f}} V D_{1 \mathrm{I}}}{g_{\mathrm{c}} \mu_{\mathrm{f}}}=39,810 \text {, }
$$

where $\mu_{\mathrm{f}}=$ dynamic viscosity for water.

The flow is turbulent, and the friction factor for smooth walls is

$$
f=(0.316) / R_{\mathrm{e}}^{1 / 4}=0.02237 \text {. }
$$

With this, the pressure drop along the length, $L$, is

$$
\Delta R_{\mathrm{L}}=f \frac{\mathrm{L}}{D} \rho_{\mathrm{f}} \frac{V^{2}}{2}=\frac{0.158}{g_{\mathrm{c}}^{0.75}} \frac{\mathrm{L}}{D^{1.25}} \mu_{\mathrm{f}}^{0.25} \rho_{\mathrm{f}}^{0.75} V^{1.75}=658.4 \mathrm{kPa}(95.5 \mathrm{psi}) .
$$

This value is a reasonable approximation of the pressure loss reported during operation of the HFIR reactor. Using Eq. (B.4) the pressure loss in the proposed ANS lower plates at an operating velocity of $27.4 \mathrm{~m} / \mathrm{s}$ is estimated at $\Delta P_{\mathrm{L}}=1.534 \mathrm{MPa}(222.5 \mathrm{psi})$. The pressure loss for the epoxy plate model at the model operating velocity of $5.66 \mathrm{~m} / \mathrm{s}$ (scaled from the prototype velocity) is estimated as $\Delta P_{\mathrm{L}}=0.097 \mathrm{MPa}(14.1 \mathrm{psi})$. 


\section{Distribution}

1. C. W. Alexander

2. D. J. Alexander

3. R. R. Allen

4. E. E. Alston

5. J. L. Anderson

6. B. R. Appleton

7. R. L. Battiste

8. R. S. Booth

9. W. W. Bowman

10. R. A. Brown

11. G. J. Bunick

12-16. J. H. Campbell

17. P. F. Cento

18. N. C. J. Chen

19. K. K. Chipley

20. J. E. Cleaves

21. J. T. Cleveland

22. J. A. Clinard

23. G. L. Copeland

24. B. L. Corbett

25. J. M. Corum

26. J. R. Dixon

27. F. F. Dyer

28. D. K. Felde

29. R. E. Fenstermaker

30. M. L. Gildner

31. H. A. Glovier

32. R. C. Gwaltney

33. R. M. Harrington
34. J. B. Hayter

35. W. R. Hendrich

36. S. E. Holliman

37. M. M. Houser

38. D. T. Ingersoll

39-42. R. L. Johnson

43. J. E. Jones, Jr.

44. R. A. Lillie

45. M. A. Linn

46. A. T. Lucas

47. C. R. Luttrell

48. M. F. Marchbanks

49. J. A. March-Leuba

50. B. S. Maxon

51. G. T. Mays

52. S. V. McGrath

53. T. J. McManamy

54. G. R. McNutt

55. J. T. Mihalczo

56. B. H. Montgomery

57. R. M. Moon

58. D. G. Morris

59. D. L. Moses

60. R. E. Pawel

61. H. R. Payne

62. F. J. Peretz

63. A. B. Poole

64. C. C. Queen

65. S. Raman
66. C. T. Ramsey

67. J. S. Rayside

68. J. P. Renier

69. J. B. Roberto

70. M. B. Ruggles

71. T. L. Ryan

72. D. L. Selby

73. H. B. Shapira

74. M. Siman-Tov

75. B. R. Smith

76. W. F. Swinson

77. R. P. Taleyarkhan

78. D. W. Thiesen

79. P. B. Thompson

80. K. R. Thoms

81. S. R. Tompkins

82. B. D. Warnick

83. C. D. West

84. J. L. Westbrook

85. D. M. Williams

86. B. A. Worley

87. G. T. Yahr

88. G. L. Yoder

89. ORNL Patent Section

90-91. Document Res. Library

92. Y-12 Technical Library

93. Laboratory Records Dept.

94-95. Laboratory Records (RC)

\section{External Distribution}

96. R. Awan, U.S. Department of Energy, NE-473, Washington, DC 20585.

97. C. L. Christen, DRS/Hundley Kling Gmitter, 1055 Commerce Park Drive, Oak Ridge, TN 37830.

98-103. U.S. Department of Energy, ANS Project Office, Oak Ridge Field Office, FEDC, MS-8218, P.O. Box 2009, Oak Ridge, TN 37831-8218.

104. R. R. Fullwood, Brookhaven National Laboratory, Upton, NY 11973.

105. R. Gambill, Route 5, Box 220, Clinton, TN 37716.

106. B. Gupta, AECL Technologies, 1155 Metcalfe Street, 2nd Floor, Montreal, Quebec, Canada H3B 2 V6.

107. A. F. Henry, Professor, Department of Nuclear Engineering, Massachusetts Institute of Technology, 77 Massachusetts Avenue, Cambridge, MA 02139.

108. R. A. Hunter, Director, Office of Facilities, Fuel Cycle, and Test Programs, Nuclear Energy Division, U.S. Department of Energy, NE-47, Washington, DC 20585. 
109. L. C. Ianniello, Acting Associate Director, Office of Basic Energy Sciences, Office of Energy Research, U. S. Department of Energy, ER-10, Washington, DC 20585.

110. T. L. Kerlin, University of Tennessee, College of Engineering, 315 Pasqua Engineering Building, Knoxville, TN 37996-2300.

111. J. A. Lake, Manager, Nuclear Engineering and Reactor Design, Idaho National Engineering Laboratory, P. O. Box 1625, Idaho Falls, ID 83415.

112. J. E. Mays, Research and Test Reactor Fuel Elements, Babcock and Wilcox Co., P. O. Box 785, Lynchburg, VA 24505.

113-114. W. E. Meek, Project Manager, Gilbert/Commonwealth, Inc., P. O. Box 1498, Reading, PA 19603.

115. J. P. Mulkey, U.S. Department of Energy, NE-473, Washington, DC 20585.

116. W. T. Oosterhuis, Materials Sciences Division, Office of Basic Energy Sciences, Office of Energy Research, U.S. Department of Energy, ER-132, Washington, DC 20585.

117. H. Reutler, Siemens, Friedrich-Ebert Strasse, D-5060 Bergish, Gladbach-1, Germany.

118. J. M. Ryskamp, Idaho National Engineering Laboratory, P. O. Box 1625, Idaho Falls, ID 83415-3885.

119. J. L. Snelgrove, Coordinator, Engineering Applications, RERTR Program, Argonne National Laboratory, 9700 South Cass Avenue, Argonne, IL 60439.

120. P. I. Stumbo, U.S. Department of Energy, Oak Ridge Operations Office, P. O. Box 2001, Oak Ridge, TN 37831.

121. I. Thomas, Director, Materials Science Division, Office of Energy Research, U.S. Department of Energy, ER-13, Washington, D.C. 20585.

122. J. M. Warren, Gilbert/Commonwealth, Inc., 1055 Commerce Park Drive, Suite 200, Oak Ridge, TN 37830.

123. P. W. Winkler, Air Products and Chemicals, Inc., 7201 Hamilton Boulevard, Allentown, PA 18195-1501.

124. H. G. Wood, III, Associate Professor, Department of Mechanical and Aerospace Engineering, Thornton Hall, University of Virginia, Charlottesville, VA 22901

125. Office of Assistant Manager for Energy Research and Development, U.S. Department of Energy, Oak Ridge Operations Office, P. O. Box 2001, Oak Ridge, TN 37831.

126-127. Office of Scientific and Technical Information, P. O. Box 62, Oak Ridge, TN 37831. 

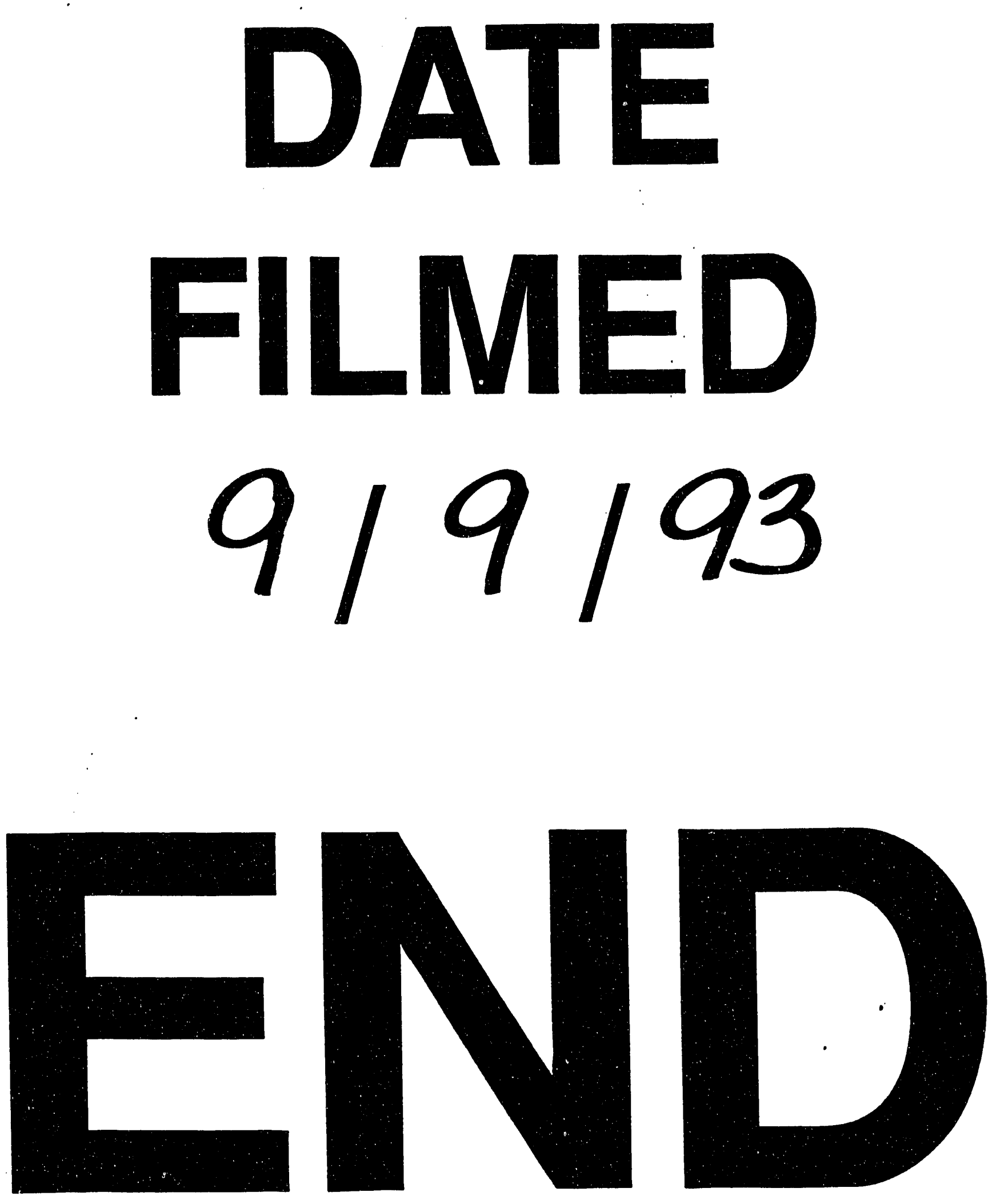
